\title{
Evaluation of the Diurnal Cycle in the Atmospheric Boundary Layer Over Land as Represented by a Variety of Single-Column Models: The Second GABLS Experiment
}

\author{
G. Svensson - A. A. M. Holtslag • V. Kumar - T. Mauritsen - G. J. Steeneveld • \\ W. M. Angevine · E. Bazile - A. Beljaars · E. I. F. de Bruijn · A. Cheng • \\ L. Conangla - J. Cuxart - M. Ek - M. J. Falk - F. Freedman - H. Kitagawa • \\ V. E. Larson - A. Lock · J. Mailhot • V. Masson · S. Park · J. Pleim · \\ S. Söderberg · W. Weng · M. Zampieri
}

Received: 10 March 2010 / Accepted: 22 March 2011 / Published online: 1 May 2011 (C) Springer Science+Business Media B.V. 2011

Abstract We present the main results from the second model intercomparison within the
GEWEX (Global Energy and Water cycle EXperiment) Atmospheric Boundary Layer Study
(GABLS). The target is to examine the diurnal cycle over land in today's numerical weather
prediction and climate models for operational and research purposes. The set-up of the

G. Svensson $(\bowtie)$

Department of Meteorology, Stockholm University, Stockholm, Sweden e-mail: gunilla@misu.su.se

A. A. M. Holtslag · G. J. Steeneveld

Meteorology and Air Quality Section, Wageningen University, Wageningen, The Netherlands

V. Kumar

Department of Geography and Environmental Engineering, Johns Hopkins University, Baltimore, MD, USA

T. Mauritsen

Max Planck Institute for Meteorology, Hamburg, Germany

W. M. Angevine

CIRES, University of Colorado, Boulder, CO, USA

W. M. Angevine

NOAA ESRL, Boulder, CO, USA

E. Bazile · V. Masson

CNRM (National Centre for Meteorological Research)-GAME, Météo-France/CNRS, Toulouse, France

A. Beljaars

European Centre for Medium-Range Weather Forecast, Reading, UK

E. I. F. de Bruijn

KNMI, Royal Netherlands Meteorological Institute, De Bilt, The Netherlands

A. Cheng

Science Systems and Applications, Inc., Hampton, VA, USA 
case is based on observations taken during the Cooperative Atmosphere-Surface Exchange Study-1999 (CASES-99), which was held in Kansas, USA in the early autumn with a strong diurnal cycle with no clouds present. The models are forced with a constant geostrophic wind, prescribed surface temperature and large-scale divergence. Results from 30 different model simulations and one large-eddy simulation (LES) are analyzed and compared with observations. Even though the surface temperature is prescribed, the models give variable near-surface air temperatures. This, in turn, gives rise to differences in low-level stability affecting the turbulence and the turbulent heat fluxes. The increase in modelled upward sensible heat flux during the morning transition is typically too weak and the growth of the convective boundary layer before noon is too slow. This is related to weak modelled nearsurface winds during the morning hours. The agreement between the models, the LES and observations is the best during the late afternoon. From this intercomparison study, we find that modelling the diurnal cycle is still a big challenge. For the convective part of the diurnal cycle, some of the first-order schemes perform somewhat better while the turbulent kinetic

A. Cheng

Langley Research Center, NASA, Hampton, VA, USA

L. Conangla

Departament de Física Aplicada, Universitat Politècnica de Catalunya, Manresa, Spain

J. Cuxart

Departament de Física, Grup de Meteorologia, Universitat de les Illes Balears, Ciutat de Mallorca, Spain

M. Ek

NOAA Science Center, National Centers for Environmental Prediction/Environmental Modeling Center, Camp Springs, MD, USA

M. J. Falk · V. E. Larson

Department of Mathematical Sciences, University of Wisconsin, Milwaukee, WI, USA

F. Freedman

San Jose State University, San Jose, CA, USA

H. Kitagawa

Japan Meteorological Agency, Tokyo, Japan

A. Lock

Met Office, Exeter, UK

J. Mailhot

Meteorological Research Division, Environment Canada, Dorval, QC, Canada

S. Park

Climate and Global Dynamics Division, National Center for Atmospheric Research, Boulder, CO, USA

J. Pleim

U.S. Environmental Protection Agency, Research Triangle Park, NC, USA

S. Söderberg

WeatherTech Scandinavia, Uppsala, Sweden

W. Weng

York University, Toronto, ON, Canada

M. Zampieri

ISAC-CNR, Bologna, Italy 
energy (TKE) schemes tend to be slightly better during nighttime conditions. Finer vertical resolution tends to improve results to some extent, but is certainly not the solution to all the deficiencies identified.

Keywords Diurnal cycle · GABLS · Model intercomparison - Single-column models · Turbulence parametrizations

\section{Introduction}

The overall goal of the GEWEX (Global Energy and Water cycle EXperiment) Atmospheric Boundary Layer Study (GABLS) is to improve the representation of the atmospheric boundary layer in weather and climate models. This will also benefit air quality and earth system studies (Holtslag 2003, 2006; Teixeira et al. 2008). The first GABLS study (GABLS1) examined the performance of planetary boundary-layer (PBL) schemes for a weakly stably stratified case, generated with a constant background geostrophic wind speed and a constant surface cooling rate. This idealized case was simulated by single column models (SCMs, Cuxart et al. 2006) as well as large-eddy simulations (LES, Beare et al. 2006). The main conclusions from GABLS1 are that the state-of-the-art LES available during that time were able to simulate the case with reliable statistics and that the operational models simulated a stable boundary layer that was too deep. For a further discussion of the results, we refer to Cuxart et al. (2006), Beare et al. (2006), as well as Svensson and Holtslag (2009).

For the present study, the second GABLS case (GABLS2), the central goal is to examine how well the diurnal cycle over land is represented by boundary-layer schemes used in today's numerical weather prediction and climate models for operational and research purposes. While the first experiment was an idealized study, the set-up of GABLS2 is based on observations taken in Kansas, USA in the early autumn during the Cooperative AtmosphereSurface Exchange Study-1999 (CASES-99, Poulos et al. 2002). Two consecutive clear days from the CASES-99 data, which indicated a strong diurnal cycle over relatively dry land, were selected for the intercomparison study. It is noted that Steeneveld et al. (2006) performed a case study with these data and found good agreement with their model set-up that allowed for surface feedback and radiation processes in addition to turbulence. In the present study, we focus on the intercomparison of boundary-layer schemes, and so the forcing conditions have been simplified to facilitate a straightforward comparison between the model closures rather than detailed comparison with observations.

Extensive model evaluations of the diurnal cycle of PBL properties are scarce in the recent literature, and very few studies have been performed with the PBL scheme in full interaction with other model components in weather forecast models (e.g. Zhang and Zheng 2004; Tjernström et al. 2005; Steeneveld et al. 2008) or climate models (e.g. Dai and Trenberth 2004). In the current case, simple forcings of constant geostrophic wind, prescribed surface temperature and large-scale divergence were applied. However, in the real world such 'golden' or 'textbook' cases do not occur. For example, during the selected period, the geostrophic wind was not constant. As will be discussed later, the selected method of prescribing the surface temperature also caused some difficulties in interpreting the results.

In the present study, model results from 30 different model simulations are evaluated. The models range from research models with higher-order closures and fine vertical resolution to operational models using first-order closures and a coarse grid. The set-up of 
the experiment and the participating models are described in Sect. 2, and Sect. 3 summarizes the observational dataset and the model forcings. In Sect. 4, the model results of the near-surface properties and vertical structure are compared with each other and with observations. The SCM results are also compared with results from a LES using identical forcing as the SCM. In Sect. 5, more general features of the diurnal cycle are discussed, and finally a short discussion and conclusions are presented in Sect. 6.

\section{Case Set-up and Participating Models}

When designing the model intercomparison case study, our purpose was to keep the set-up of the simulation as simple as possible to allow for many groups to participate and to ensure that model specific implementation of more complicated processes would not obscure the analysis. The models are driven by a prescribed surface temperature, constant geostrophic wind in time and space of about $9.5 \mathrm{~m} \mathrm{~s}^{-1}$, and a small subsidence rate $\left(0.005 \mathrm{~m} \mathrm{~s}^{-1}\right)$ representing the effect of the large-scale divergence starting in the afternoon of 23 October 1999. See the Appendix for the exact description of the simulation set-up and Sect. 3 for a discussion of the observations that were used for the set-up and model evaluation.

The participating models are presented in Table 1 . The model acronym, the type of closure and responsible model centre with contact person along with main model references are given in this Table. More information on closure types can be found in Cuxart et al. (2006). Some model centres have completed simulations with more than one closure and/or vertical resolution. These simulations are also listed in Table 1 along with comments on the specific run. The list includes several large numerical weather prediction centres, a global climate model as well as a variety of research models. It is noted that most of the model simulations were completed during 2005, and some of the participants have updated their PBL schemes since then, partly as a result of the discussions held within the GABLS community.

The experimental set-up did not include specific requirements on the vertical grid (see Appendix) since many of the operational models are optimized for their specific grid. To examine if there is a significant influence on the near-surface variables by the vertical grid, the models are divided into groups based on the height to the first model level for mean quantities. The majority of the models use staggered grids. In Table 2, the participating models are listed in four groups depending on their level of closure, first-order- or turbulent kinetic energy (TKE)-based schemes, and whether the height to the first model level is below or above $5 \mathrm{~m}$. Table 2 also contains some information about the model grids used in the simulations.

In addition to the SCM, we show results from a LES with domain size of $4000 \times 4000 \times$ $2000 \mathrm{~m}^{3}$, with 128 computational nodes in each direction giving resolutions of 31.2 and $15.6 \mathrm{~m}$ in the horizontal and vertical, respectively. The subgrid-scale momentum and heat flux relations are of the eddy-viscosity type and are modelled using a Lagrangian dynamic scale-dependent subgrid-scale model (Bou-Zeid et al. 2005). A detailed description of the LES code can be found in Kumar et al. (2006) and a discussion of the LES results from the GABLS2 case is presented in Kumar et al. (2010).

\section{CASES-99 Observations and Model Forcings}

The CASES-99 dataset was collected during October 1999 in Kansas, USA $\left(37.6^{\circ} \mathrm{N}\right.$, $\left.96.7^{\circ} \mathrm{W}\right)$. At this time of the year, the conditions are very dry in the region with very few clouds. The area is rather flat with a surface roughness of about $0.03 \mathrm{~m}$. Observations were 


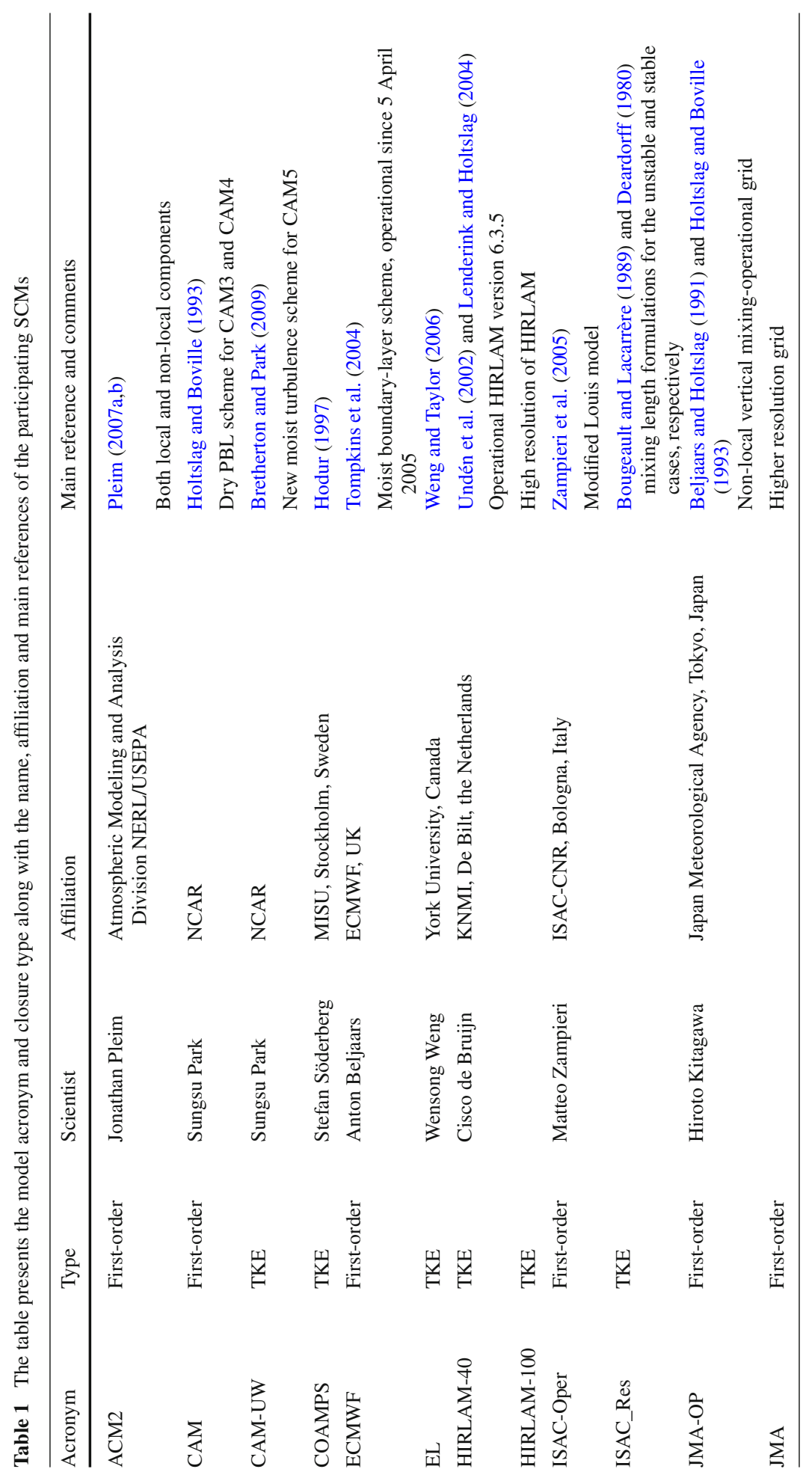




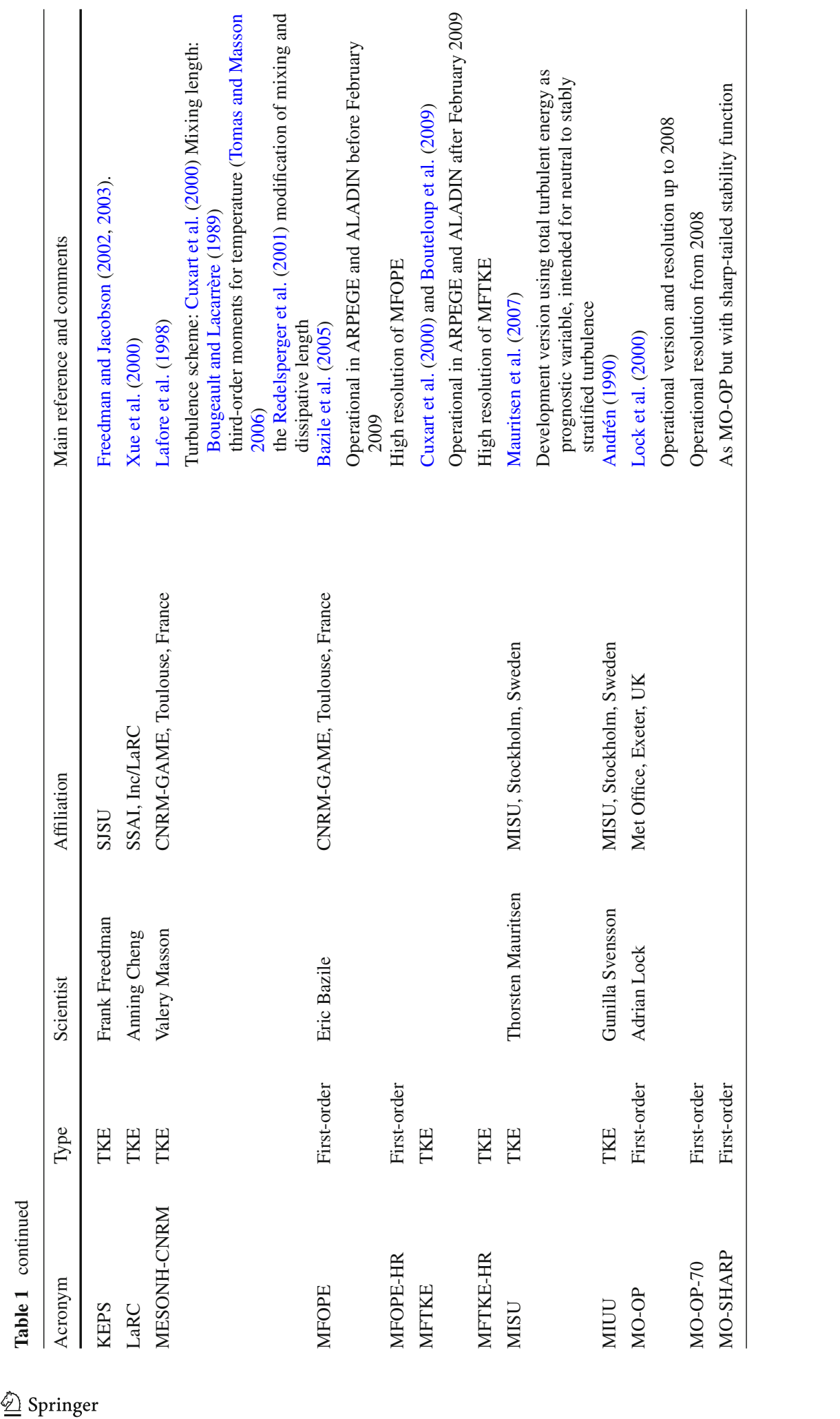




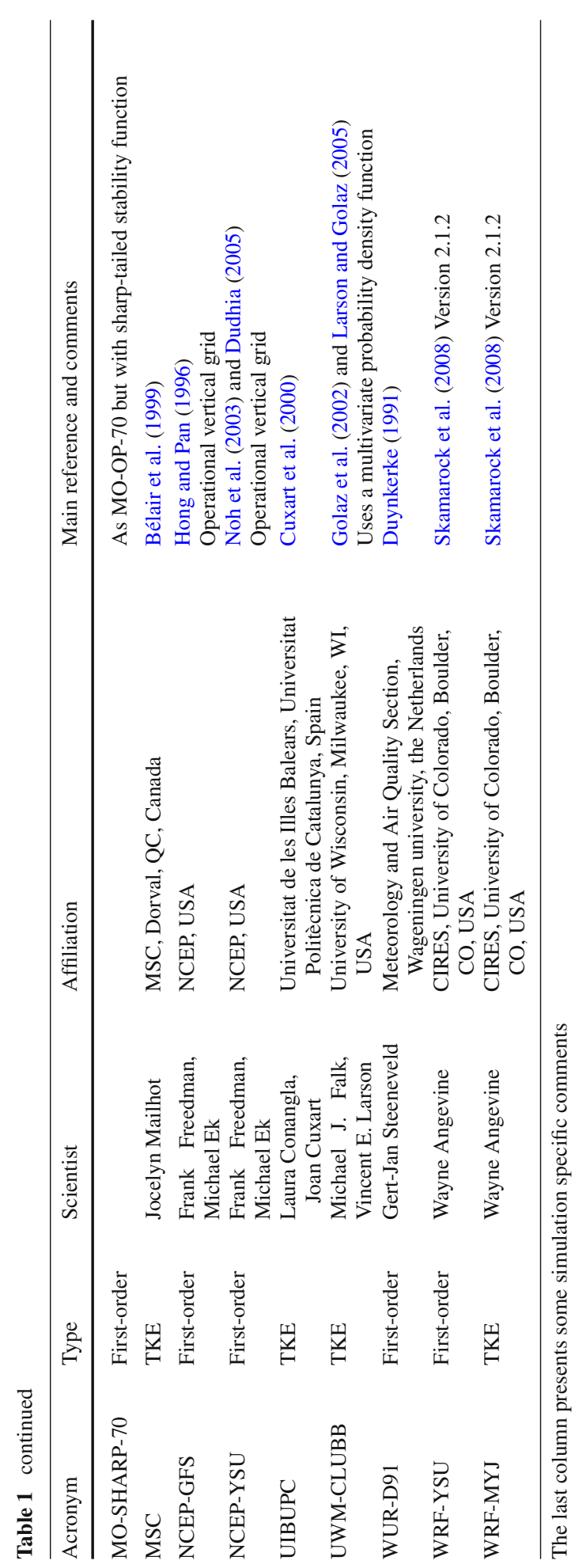


Table 2 The table presents the SCMs (see Table 1) divided in four categories based on model closure and height to the first model level, see text for discussion

Model Number of grid levels Lowest gridpoint (m) Levels below $1000 \mathrm{~m}$ Model top (m) below $4000 \mathrm{~m}$ (total)

(a) First-order models with lowest gridpoint below $5 \mathrm{~m}$

$\begin{array}{lllrr}\text { ACM2 } & 60 & 4 & 29 & 4000 \\ \text { ISAC-Oper } & 184(201) & 1.5 & 111 & 5400 \\ \text { JMA } & 177(200) & 2 & 101 & 5900 \\ \text { MFOPE-HR } & 100 & 2 & 49 & 4000 \\ \text { MO-OP-70 } & 24(70) & 3.5 & 12 & 62000 \\ \text { MO-SHARP-70 } & 24(70) & 3.5 & 12 & 62000 \\ \text { WUR-D91 } & 51 & 1 & 24 & 4000\end{array}$

(b) First-order models with lowest gridpoint above $5 \mathrm{~m}$

$\begin{array}{lllrr}\text { CAM } & 11(30) & 62.5 & 6 & 39000 \\ \text { ECMWF } & 19(21) & 10 & 10 & 5000 \\ \text { JMA-OP } & 12(40) & 42 & 5 & 50000 \\ \text { MFOPE } & 18 & 17 & 8 & 4000 \\ \text { MO-OP } & 14(38) & 10 & 7 & 36000 \\ \text { MO-SHARP } & 14(38) & 10 & 7 & 36000 \\ \text { NCEP-GFS } & 21(64) & 22 & 11 & 33000 \\ \text { NCEP-YSU } & 21(64) & 22 & 11 & 33000 \\ \text { WRF-YSU } & 40 & 24 & 16 & 4000\end{array}$

(c) TKE models with lowest gridpoint below $5 \mathrm{~m}$

$\begin{array}{lllrr}\text { COAMPS } & 71(99) & 1 & 41 & 25000 \\ \text { COSMO } & 97(98) & 0.6 & 53 & 4000 \\ \text { EL } & 151 & 1 & 53 & 4000 \\ \text { ISAC-Res } & 184(201) & 1.5 & 111 & 5400 \\ \text { MESONH-CNRM } & 100 & 1 & 67 & 4000 \\ \text { MFTKE-HR } & 100 & 2 & 49 & 4000 \\ \text { MISU } & 120(120) & 2 & 55 & 2300 \\ \text { MIUU } & 65 & 0.5 & 28 & 4000 \\ \text { UIBUPC } & 399 & 5 & 100 & 4000 \\ \text { UWM-CLUBB } & 399 & 5 & 100 & 4000\end{array}$

(d) TKE models with lowest gridpoint above $5 \mathrm{~m}$

$\begin{array}{lllrr}\text { CAM_UW } & 11(30) & 62.5 & 6 & 39000 \\ \text { HIRLAM-40 } & 18(40) & 32 & 9 & 56000 \\ \text { HIRLAM-100 } & 57(100) & 18 & 24 & 21000 \\ \text { KEPS } & 33(60) & 20 & 17 & 21000 \\ \text { LaRC } & 40 & 8 & 16 & 4000 \\ \text { MFTKE } & 18 & 17 & 8 & 4000 \\ \text { MSC } & 82 & 25 & 21 & 4000 \\ \text { WRF-MYJ } & 40 & 24 & 16 & 4000\end{array}$

Also presented in the table is some information on the vertical grid used in the simulations 
taken continuously during a month with intensified activities during some nights. For detailed information of the experiment and the instrumentation, we refer to Poulos et al. (2002) and http://www.cora.nwra.com/cases/CASES-99.html. The observations used here are from the heavily instrumented main tower $(55 \mathrm{~m}$ tall) and the 10 - $\mathrm{m}$ tower operated by the University of Wageningen group (Hartogensis and de Bruin 2005; Steeneveld et al. 2006). These towers provide observations of both mean and turbulent quantities. Observations taken at the outer network, a triangle with approximate sides of $64 \mathrm{~km}$ provided by the Atmospheric Boundary Layer Experiments (ABLE, LeMone et al. 2000), are used here along with soundings released close to the main site.

Generating an atmospheric observational dataset that exhibits quasi-stationary conditions in a location that is horizontally homogeneous is extremely difficult. Even for the month of CASES-99 observations, only one diurnal cycle could be found with sufficiently unchanging synoptic conditions. It is preferable to use a constant geostrophic wind to force the SCMs. At the time of designing the experiment, only the soundings were available to derive the forcing. To examine the large-scale flow and the representativeness of the selected forcing, we have diagnosed the geostrophic wind from the pressure field of a three-dimensional simulation using COAMPS ${ }^{\circledR}$ (Hodur 1997). For information on the details of this regional simulation, see Steeneveld et al. (2008).

Figure 1 shows the results from this analysis along with observed wind speed and direction from the soundings and the prescribed geostrophic wind for the SCM experiment. All data are height-averaged over the interval 3-4 km a.g.l., i.e. above the local PBL. Note that there is a gap of $20 \mathrm{~h}$ in the soundings during the first day. The analysis of the regional model simulation revealed that the geostrophic wind was approximately constant for the first $12 \mathrm{~h}$ and followed by an almost linear decrease for the next $24 \mathrm{~h}$. The two soundings made during the day and evening of 23 October show a higher wind speed than the diagnosed geostrophic wind. Until the morning of 24 October, the wind speed in COAMPS is higher than that motivated by the pressure field, indicating an ageostrophic contribution.

From this analysis, we conclude that the geostrophic forcing used in the SCM simulations during the first $16 \mathrm{~h}$ is too weak and afterwards it is too strong. There is very little directional change before the morning of 24 October, see Fig. 1b. After that period, there are other significant changes in wind speed and direction as well as temperature (not shown) that end the quasi-stationary conditions required for the comparison with data. Omitting the first hours of the SCM simulations for spin-up thus allows the comparison with data from 2000 local time (LT) 22 October to 070024 October (0100 UTC 23 October-1200 UTC 24 October), i.e. two full nights and the intermediate day.

Figure 2 shows the prescribed skin temperatures, using sinusoidal function during daytime and a linear function during the night (see Appendix). Also shown in the figure are the observed surface temperatures for the larger network. It is clear that surface temperature is a difficult parameter to observe and to interpret. The variability of the surface temperature over the area is considerable both during night and day (about $5 \mathrm{~K}$ ), and the fitted function is in the centre of the range during nighttime and at the lower end during daytime since the observed 2-m temperatures at the central tower exhibit values in the lower range (Fig. 3).

\section{Single-Column Model Results}

As stated before, the SCM results are presented in groups categorized based on their turbulence closure and the vertical resolution. In the figures, results from the evening on 22 October to the early morning on the 24 October (see above) are presented. In addition to the 

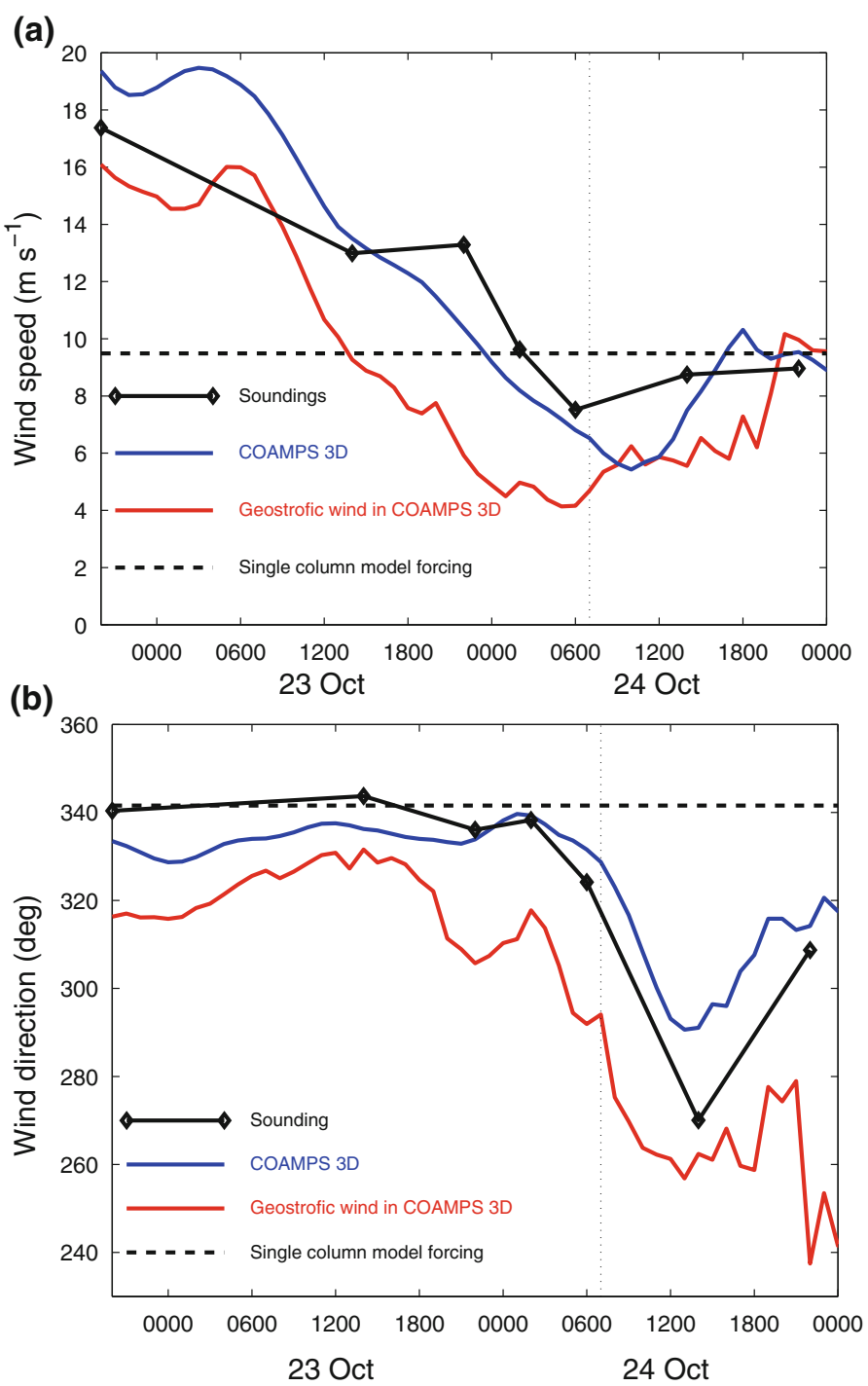

Fig. 1 Time series of background $\mathbf{a}$ wind speed $\left(\mathrm{m} \mathrm{s}^{-1}\right)$ and $\mathbf{b}$ direction (degrees) for the simulated period. Shown in the figure is the averaged wind over $3-4 \mathrm{~km}$ a.g.l. observed by soundings (black diamond) with linear interpolation (black line), simulated wind (blue) and diagnosed geostrophic wind (red) from a threedimensional simulation with COAMPS. The thick dashed line shows the geostrophic wind used as background forcing in the SCM runs (see Appendix). The thin dotted lines show the end of the analyzed period

SCM results (see Table 3 for the individual model's legend), LES results (thick dashed line) and observations (grey shades) are presented.

To facilitate the model intercomparison and interpretation of the results, we first recall the usual model formulations for the surface turbulence fluxes of sensible heat $(H)$ and momentum $(\tau)$ fluxes: 


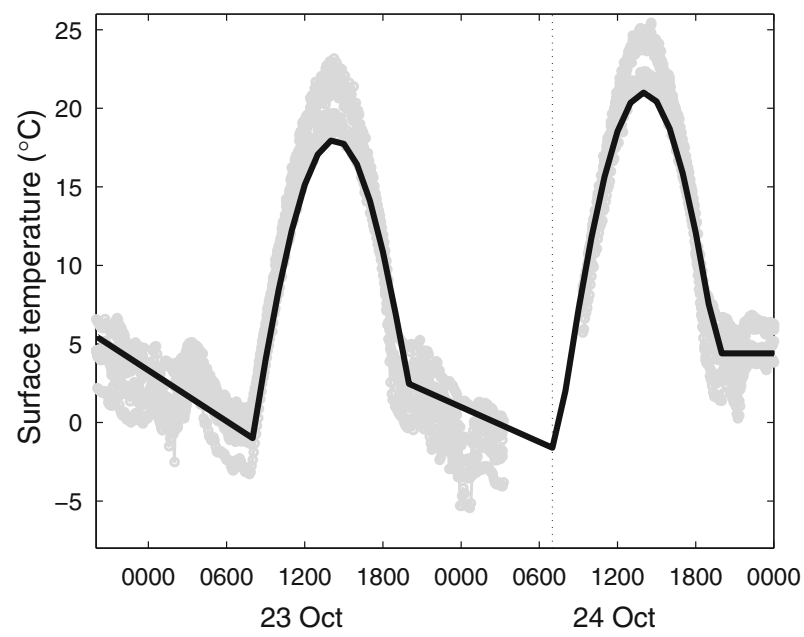

Fig. 2 Surface temperature $\left({ }^{\circ} \mathrm{C}\right)$ from observations (grey) and the fitted function (black) that is given as input to the SCM and LES for the simulated period (see Appendix). The thin dashed lines show the end of the analyzed period

Table 3 Reference legend for the SCM (see Table 1) results presented in Figs. 3-16

First-order closure, $z_{1} \leq 5 \mathrm{~m} \quad$ First-order closure, $z_{1}>5 \mathrm{~m}$

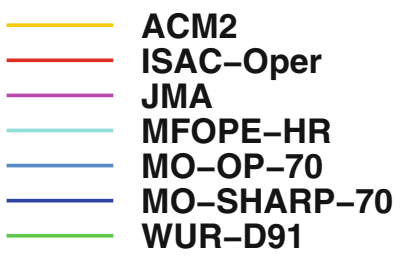

TKE closure, $\mathrm{z}_{1} \leq 5 \mathrm{~m}$

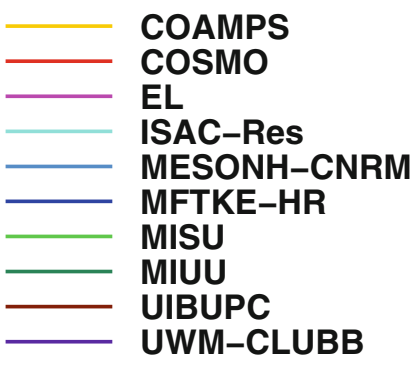

CAM

ECMWF

JMA-OP

MFOPE

MO-OP

MO-SHARP

NCEP-GFS

NCEP-YSU

WRF-YSU

The models are divided into the four categories based on closure type and height to the first model level that are presented in panel a-d in the figures 


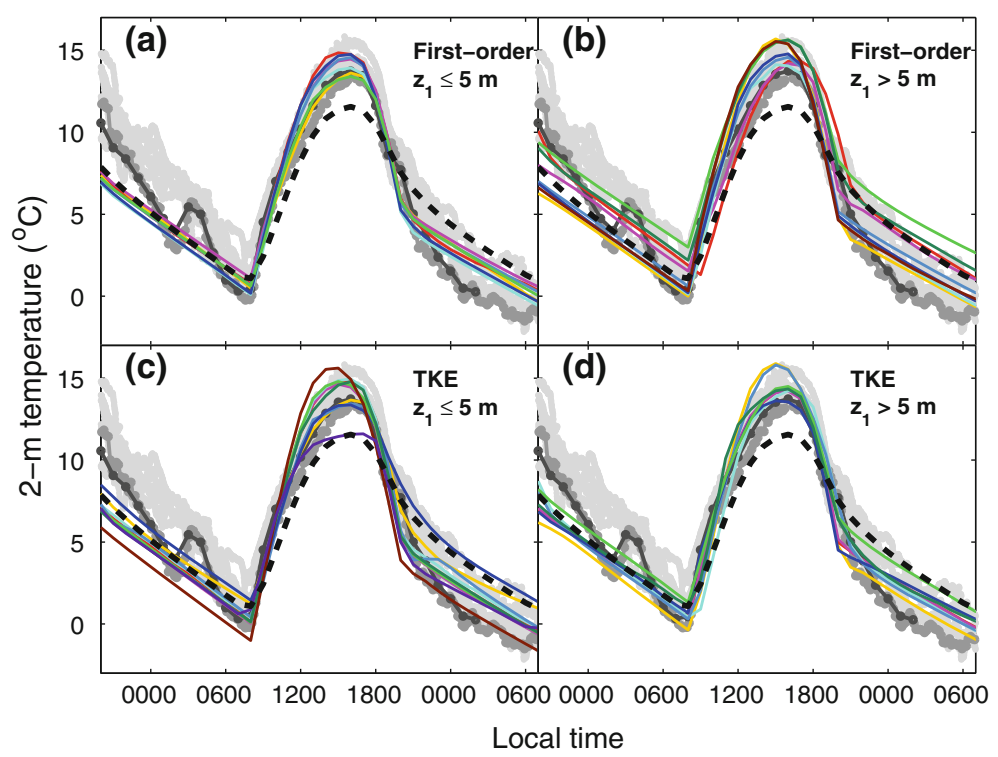

Fig. 3 Time series of observed and modelled temperature $\left({ }^{\circ} \mathrm{C}\right)$ at $2 \mathrm{~m}$ a.g.1. Light grey markers show observations from the outer network, dark grey lines with dots are observations made from the central tower (darkest shade) and nearby Wageningen tower and thick black dashed line is the LES result. The SCM results are presented in four categories based on model closure $\mathbf{a}, \mathbf{b}$ first-order closures; $\mathbf{c}, \mathbf{d}$ TKE-based schemes; and on height to the first model layer below $(\mathbf{a}, \mathbf{c})$ or above $(\mathbf{b}, \mathbf{d}) 5 \mathrm{~m}$ a.g.l. See Table 3 for legend

$$
\frac{H}{\rho C_{\mathrm{p}}}=\overline{w^{\prime} \theta^{\prime}}{ }_{0}=C_{\mathrm{H}} U_{\mathrm{r}}\left(\Theta_{0}-\Theta_{\mathrm{r}}\right),
$$

and

$$
\frac{\tau}{\rho} \equiv\left({\overline{u^{\prime} w_{0}^{\prime}}}_{0}^{2}+{\overline{v^{\prime} w^{\prime}}}_{0}^{2}\right)^{1 / 2}=u_{*}^{2}=C_{\mathrm{D}} U_{\mathrm{r}}^{2},
$$

where $C_{\mathrm{D}}$ is the stability-dependent drag coefficient, and $C_{\mathrm{H}}$ is the transfer coefficient for heat (e.g. Stull 1988). These expressions give the relation between the near-surface gradients evaluated from the surface to a reference height (denoted by subscripts 0 and $\mathrm{r}$, respectively) of mean potential temperature $(\Theta)$ and wind speed $(U)$ and the surface flux.

\subsection{2-m Temperature and Surface Heat Fluxes}

Figure 3 shows the modelled and observed 2-m temperature. The diurnal evolution generally follows the prescribed surface temperature (Fig. 2) but, already early in the simulation, deviations between the model results and the observations are seen with the models being significantly colder. This is somewhat unexpected since the surface temperature is prescribed in agreement with the observations during this period (see Fig. 2). The too low 2-m temperatures during the first night appears to be a common feature of all the model closures and resolutions, except for about half of the first-order models with the first model level above $5 \mathrm{~m}$ (Fig. 3b). It is noted that in the model runs, the surface roughness for temperature is specified (Appendix) to be $10 \%$ of that for momentum, as a standard ratio for homogeneous grassland following Brutsaert (1982). However, the interpretation and implementation of the surface temperature may have varied between the models and therefore may introduce an uncertainty 


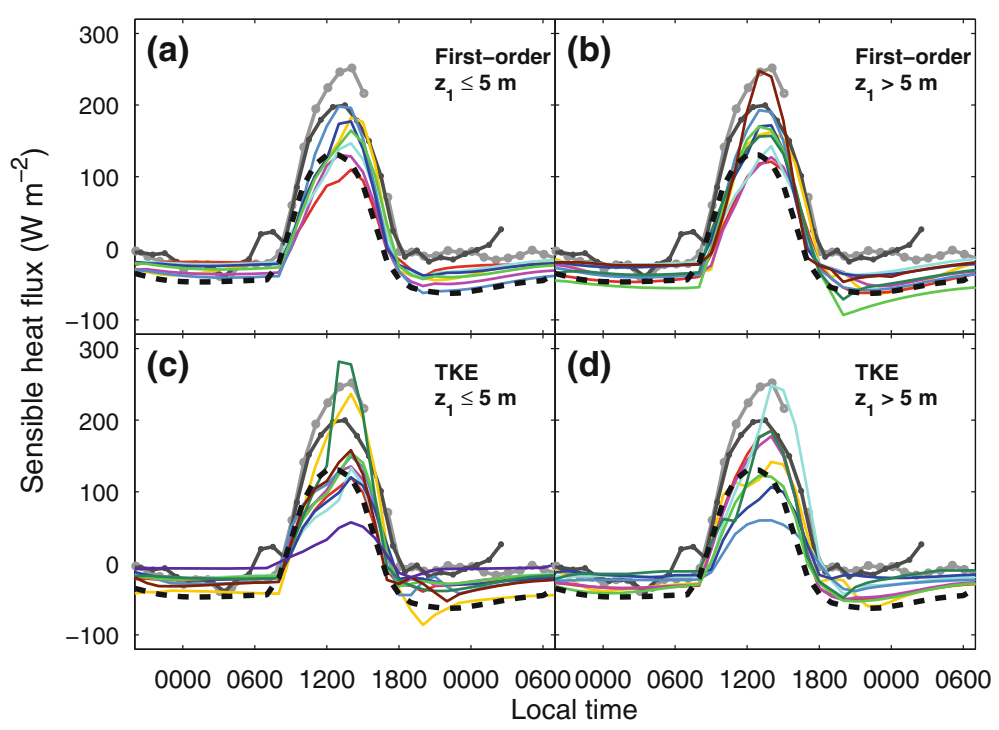

Fig. 4 Time series of observed and modelled sensible heat flux $\left(\mathrm{W} \mathrm{m}^{-2}\right)$. Dark grey lines with dots are observations made from the central tower (darkest shade) and nearby Wageningen tower and thick black dashed line is the LES result. Otherwise as in Fig. 3

into the intercomparison. Some of the discrepancy for the coarse-resolution models might also be introduced in the diagnosis of the 2-m temperature.

The transition from night-to-day is clearly dictated by the surface temperature, and all models show a distinct transition (Fig. 3). The observations show a 4-K increase in the first hour. Three of the models (one from each category except first-order closure with the first model level close to the ground) give a similar value, while the majority are in the range of $2-3 \mathrm{~K}$. The LES gives a rather slow increase of only $1.3 \mathrm{~K}$ during this first convective hour.

In the second half of the afternoon, the modelled temperature falls more rapidly than the observations (Fig. 3) even though the prescribed surface temperature does not (Fig. 2). The temperature during the second night shows a larger model spread and is positively biased in almost all models (Fig. 3), partly due to the surface forcing (Fig. 2). The LES actually has the smallest diurnal amplitude. The observations at as well as close to the central tower show a sudden increase in the temperature at about 0200 LT 23 October. This sudden increase is a local disturbance that is not expected to be simulated since it was not included in the surface forcing (see Fig. 2).

The evolution of the temperature during night and morning hours affects the PBL growth through the near-surface stability that influences the local turbulence and the surface fluxes (see Eqs. 1 and 2). Figure 4 shows the modelled heat fluxes. The variations in the surface temperatures and the difference in the maximum temperatures influence the modelled turbulence (and the mean wind as discussed later). The variations in the surface-sensible heat flux are thus very large (Fig. 4).

The range of observed sensible heat fluxes during the first night is -5 to $-30 \mathrm{~W} \mathrm{~m}^{-2}$ with the exception of the small-scale event around 0300 LT October 23 that also is evident in the near-surface temperature (see Fig. 3 and above). The models generally show greater downward heat fluxes during the night, except for the TKE models with the first grid point below $5 \mathrm{~m}$. The larger downward heat fluxes at night result from the modelled temperatures 
as well as the wind speeds as can be seen from Eq. (1). The LES downward heat flux during nighttime is greater than the observations and most SCMs. During the day, the LES heat flux is generally smaller except during the morning hours where it is increasing more rapidly than the SCMs but not as rapidly as the observations. Thus, as discussed above, the LES has a slower increase in the 2-m temperature (Fig. 3) which in turn leads to a greater heat flux since the near-surface temperature gradient is greater, given similar wind speeds (see Eq. 1). This obviously has an effect on the growth of the daytime boundary layer, see the discussion below.

The observed daytime heat fluxes are larger than those given by most models, especially during the hours before noon. The two tower observations do not show the same maximum value during the day, which could be attributed to small-scale horizontal inhomogeneity and to differences in observational methods. Different averaging times were used in the two datasets with the central tower observations including less of the mesoscale flux (Vickers and Mahrt 2003). Thus, we would expect the SCMs to be closer to the observations at the central tower, which is indeed the case. Several of the models (WRF-YSU, COAMPS, MIUU and KEPS) show a large sensible heat flux in the early afternoon, even greater than the observations while other models show a very low flux (UWM-CLUBB and LaRC have maxima below $60 \mathrm{~W} \mathrm{~m}^{-2}$ ). It is interesting to note that both the largest and the smallest daytime maxima are produced by TKE models. The models with TKE closure and the lowest level below $5 \mathrm{~m}$ are almost similar to the LES.

The CASES-99 region is very dry during the early autumn, and the surface latent heat fluxes were low, between 0 and $5 \mathrm{~W} \mathrm{~m}^{-2}$ during night and about $50 \mathrm{~W} \mathrm{~m}^{-2}$ at maximum (data from the Wageningen tower, not shown). The models show about the same range for the nighttime values and most models do not exceed $20 \mathrm{~W} \mathrm{~m}^{-2}$ during the day, i.e. a Bowen ratio of 5-15 during the day (not shown). The modelled water vapour may only affect the model results through modifications of the buoyancy calculations, since clouds were absent and the evaporative surface cooling is implicitly neglected through the prescribed surface temperature.

\subsection{0-m Wind Speed and Friction Velocity}

Figures 5 and 6 show the $10-\mathrm{m}$ wind speed and the surface friction velocity, respectively. The variability in the observed wind speed (Fig. 5) over the larger area is even more pronounced than that of the 2-m temperature (Fig. 3). The SCM results generally are within the observed range and a clear distinction between day and night is visible. The models with the first grid level closer to ground (panels a and c) show a closer agreement with each other and the observations during the first night. This is consistent with the results for the first GABLS experiment as discussed by Svensson and Holtslag (2009). The LES as well as the models with their first grid level above $5 \mathrm{~m}$ show generally a higher wind speed during the night and a smaller increase when the PBL becomes convective. The models with the coarsest vertical resolution, the two CAM versions, have a positive wind speed bias during most of the simulation (panels b and d). Another outlier is the WRF-MYJ (Fig. 5d) in which the wind speed falls almost to zero towards the end of the first night. This is connected to an imposed lower limit on the friction velocity (of $0.1 \mathrm{~m} \mathrm{~s}^{-1}$ ) apparent in Fig. $6 \mathrm{~d}$.

All models overestimate the $10-\mathrm{m}$ wind speed towards the end of the second night, and is likely to be because the forcing by the geostrophic wind is too strong (at least higher than that given by the COAMPS estimated geostrophic wind, Fig. 1). The prescribed surface cooling is also slightly weaker than that observed, at least for the beginning of the second night when observations are available (see Fig. 2). The observed stability, given by the parameter $z / L$ 


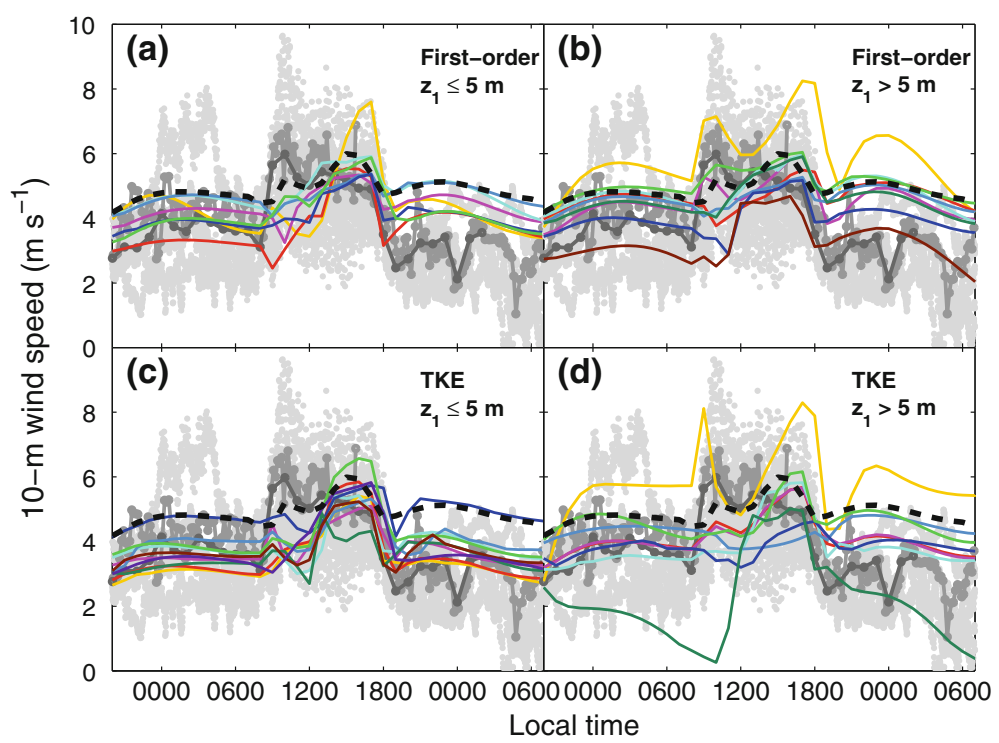

Fig. 5 Time series of observed and modelled wind speed $\left(\mathrm{ms}^{-1}\right)$ at $10 \mathrm{~m}$ a.g.l. Light grey markers show observations from the outer network, dark grey lines with dots are observations made from the central tower (darkest shade) and nearby Wageningen tower and thick black dashed line is the LES result. Otherwise as in Fig. 3

where $L$ is the Obukhov length, at $10 \mathrm{~m}$ a.g.l. is between 5 and 10 from the evening transition and until midnight of the second night, while the SCMs and LES give values between 0.5 and 2 , thereby much weaker stability (not shown). The first night also shows more stably stratified conditions in the observations compared with the SCM results initially but the difference is less after midnight. The observed 10-m wind speed (Fig. 5) as well as the friction velocity (Fig. 6) show surprisingly clear minima at the time of the evening transition. This feature is reproduced by all models regardless of closure and near-surface vertical grid resolution. Also it is noted that the peak in the friction velocity around 0200 LT 23 October is related to the local disturbance omitted in the surface temperature forcing (see Fig. 2).

All the models have difficulties in representing the near-surface variables in the morning transition; this is the most visible in the 10 -m wind speed and friction velocity. The wind speed results for the first night are represented rather well, but the friction velocities are systematically too large (Fig. 6). All of the SCMs, except the two WRF versions, and the LES overestimate the friction velocity during the night and most underestimate it during the day (Fig. 6). The latter is related to the lesser stability in the models resulting in too large values for $C_{\mathrm{D}}$ (see Eq. 2), presented in Fig. 7 evaluated over the lowest $10 \mathrm{~m}$ for the observations and SCMs. The neutral drag coefficient ${ }^{1}$ for this case is $4.7 \times 10^{-3}$; any deviations from this value reflect non-neutral conditions. In general, the models have turbulent transfer that is too efficient during the night, which leads to a small difference between night and daytime conditions. During daytime, most models show better agreement with the observations for the friction velocity and the diagnosed drag coefficient. The limitation of the friction velocity in the WRF-MYJ simulation makes the diagnosed drag coefficient behave unrealistically, an effect that seems to persist for several hours after the period when the friction velocity is limited.

1 The neutral drag coefficient is given by $C_{\mathrm{DN}}=k^{2} /\left(\ln \left(z_{\mathrm{r}} / z_{0}\right)\right)^{2}$. 


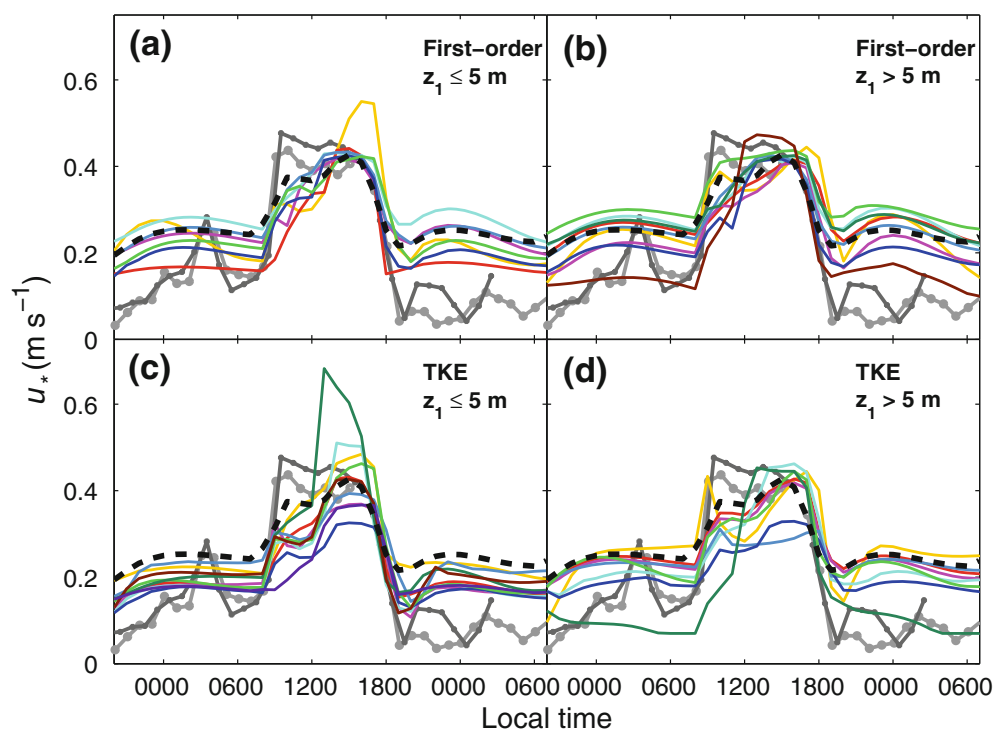

Fig. 6 Time series of observed and modelled friction velocity $\left(\mathrm{m} \mathrm{s}^{-1}\right)$. Dark grey lines with dots are observations made from the central tower (darkest shade) and nearby Wageningen tower and thick black dashed line is the LES result. Otherwise as in Fig. 3

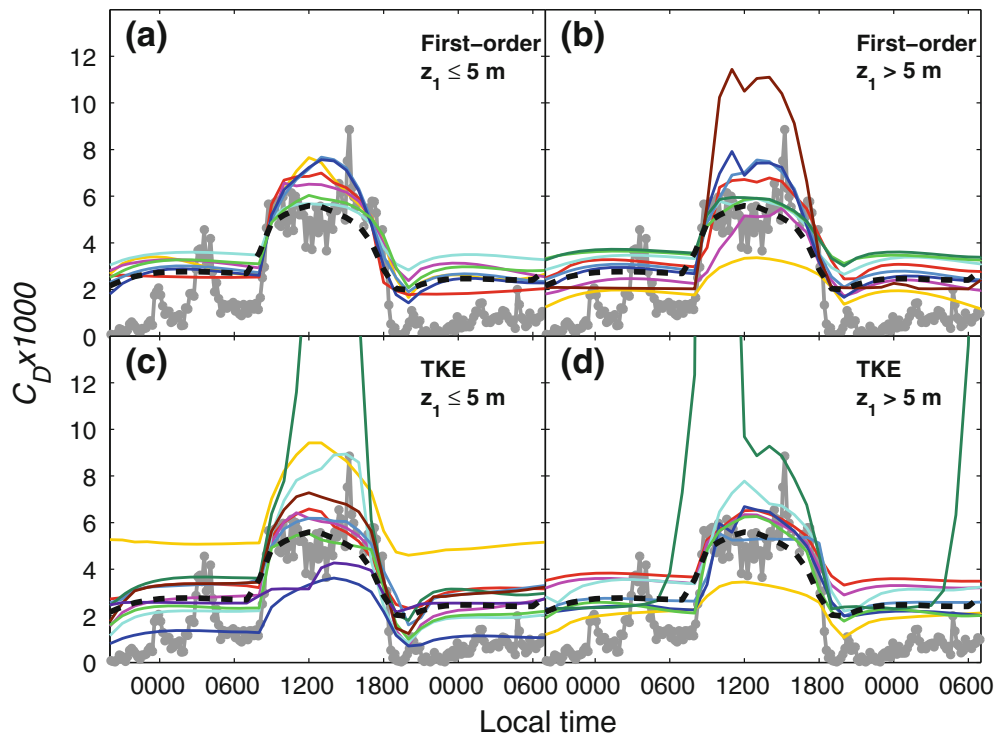

Fig. 7 Time series of drag coefficients (see Eq. 2) derived from observations and model results using the reference height $10 \mathrm{~m}$. Dark grey lines with dots are observations made from the central tower and thick black dashed line is based on the LES results. Otherwise as in Fig. 3

\subsection{Turbulent Kinetic Energy}

Figure 8 shows the observed and modelled values of turbulent kinetic energy (TKE, top panels) and vertical wind variance (lower panels). We choose to present quantities averaged over the height of the central tower (lowest $55 \mathrm{~m}$ of the atmosphere, using the instruments 


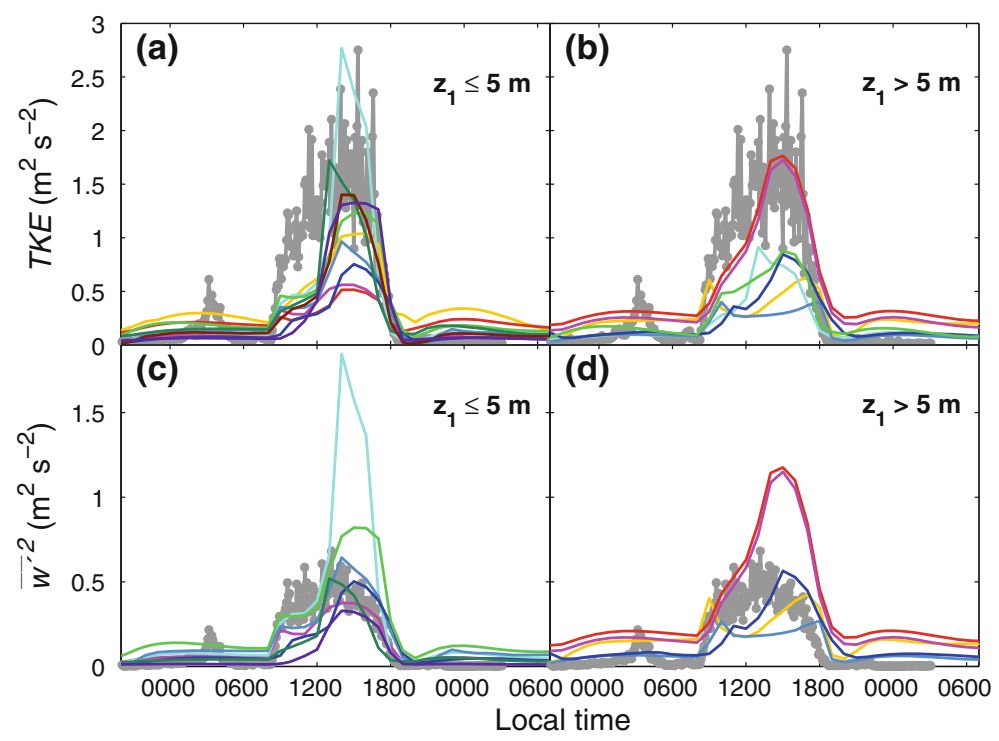

Fig. 8 Time series of observed (grey) and modelled turbulent kinetic energy $\left(\mathrm{m}^{2} \mathrm{~s}^{-2}\right.$, upper panels) and vertical wind variance $\left(\mathrm{m}^{2} \mathrm{~s}^{-2}\right.$, lower panels) averaged over the tower height $(55 \mathrm{~m})$. The SCM results for two categories based on height to the first model layer below $(\mathbf{a}, \mathbf{c})$ or above $(\mathbf{b}, \mathbf{d}) 5 \mathrm{~m}$ a.g.1 are presented. See Table 3 for legend

at $1.5,5,10,20,30,40,50$ and $55 \mathrm{~m}$ a.g.1.) and corresponding averages of the SCM results. The number of levels of the PBL models below $55 \mathrm{~m}$ varies between 1 and 18 . In general, the same picture as before arises, i.e. too much turbulence during the stably stratified night and too little during the convective day (see also Fig. 7); levels of turbulence are especially weak during the morning hours.

The layer-averaged observed TKE shows increases in the afternoon, a feature not present in the near-surface observations of other parameters (see Figs. 3, 4, 5 and 6). This observed increase could be due to horizontal variability that is not expected to be captured by the SCM. To isolate from the horizontal wind variances, also shown is the vertical wind variance (Fig. 8c, d). In comparison with the observations, most SCMs overestimate the vertical variance during the night, have too low values during the morning hours while better agreement is found in the early afternoon. A few models (ISAC-Res, MISU and the two HIRLAM versions) overestimate the vertical wind variance during the afternoon.

\subsection{Boundary-Layer Height}

The height of the turbulent layer is not easily assessed with the same method for the entire diurnal cycle. For stably stratified conditions, the height where the momentum flux has decreased to $5 \%$ of its surface value divided by 0.95 , assuming a linear decrease with height at the top of the PBL, is used. The same definition was used in GABLS1; see Cuxart et al. (2006) for a discussion on various definitions for the stably stratified turbulent layer. Figure 9 shows the results of this analysis that is only applied when the surface heat flux is downwards, i.e. nighttime conditions. There are large variations in the momentum profiles and several models, which have a slowly decreasing stress and/or significant background values, give large variations in the depth of the stable PBL. This variation seems to be larger for the 


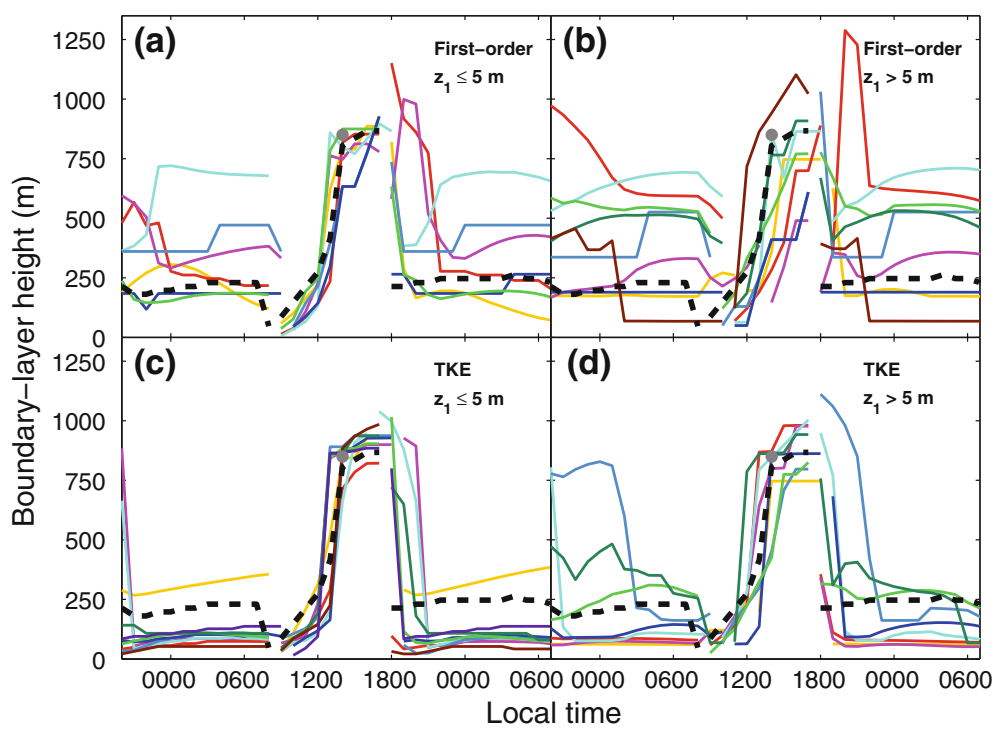

Fig. 9 Time series of modelled PBL height $(\mathrm{m})$ and the grey dot is an estimate from the $1400 \mathrm{LT}$ sounding. The estimates are based on the momentum profiles during stably stratified conditions and height to the inversion during unstable conditions, see text for further explanation. Otherwise as in Fig. 3

first-order models (panels a and b). The TKE models with their first model level close to the surface (Fig. 9c) produce the shallowest PBL and the most consistent picture. However, the inter-model spread is still large; the PBL depth varies by a factor of three (between 50 and $150 \mathrm{~m}$ ) during the first night, in agreement with findings from the first GABLS case. Estimates of the PBL height from the tower observations show a PBL depth of 20-40 m between 0000 and $0400 \mathrm{LT}$ and about $20 \mathrm{~m}$ at the evening transition on 22 October. These estimates are based mainly on the minima in the buoyancy profiles but also with supporting information from the momentum flux and turbulent energy profiles and are rather uncertain (Larry Mahrt, personal communication, 2010). Several models (MESONH-CNRM and UIBUPC) do give a PBL that is as shallow as that observed at the time of the evening transition (Fig. 9c).

For convective conditions, during daytime, the height to the capping inversion is a more appropriate estimate (Fig. 9). The estimated PBL height from the $1400 \mathrm{LT}$ sounding is $850 \mathrm{~m}$ while the LES gives $805 \mathrm{~m}$. The SCM median at this time is $800 \mathrm{~m}$, but there is quite a spread with 5 and 95 percentiles of 300 and $890 \mathrm{~m}$, respectively. The largest model spread is found for the first-order models, not only in height but also in the timing of the onset of the growth of the convective PBL. One model (JMA-OP) has a surface-based inversion until 1300 LT, and the TKE-based climate model (CAM-UW) also has no elevated inversion until after 1200 LT. These two models have their first grid point at 42 and $62.5 \mathrm{~m}$ and only five and six levels below $1000 \mathrm{~m}$, respectively, (see Table 2). This, in combination with long model timesteps, influences the PBL growth.

It is clear from Fig. 9 that the PBL in the LES grows more rapidly during the morning hours than in the SCM. The LES PBL experiences strong surface forcing via the heat flux (Fig. 4), which results in more rapid growth. It is puzzling, however, that the near-surface temperature and wind speed (Figs. 3, 5) as well as the TKE (Fig. 8) do not seem to adhere to this. Most of the SCMs and the LES show a slow morning growth up to about $500 \mathrm{~m}$, and after that the growth is almost instantaneous to a height of about $800 \mathrm{~m}$. This rapid growth occurs 


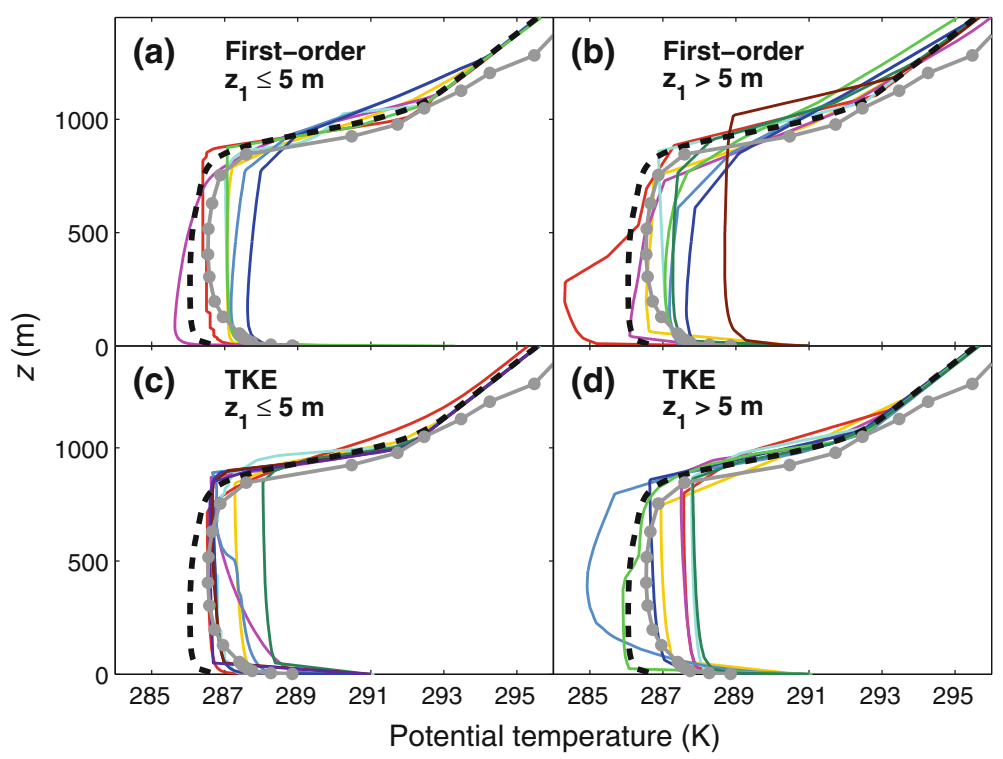

Fig. 10 Observed (grey, combined from tower and sounding) and modelled vertical profiles of potential temperature $(\mathrm{K})$ at 1400 LT 23 October. Otherwise as in Fig. 3

when the nighttime inversion is eroded and the near-neutral residual layer is reached. In the set-up of the model intercomparison, we did not allow for processes acting on the stability in the residual layer in the SCM, and thus the near-neutral stratification in this layer makes it easy to be incorporated in the PBL. In the three-dimensional COAMPS run, this layer is affected by mesoscale processes and as a result the growth through this layer is indeed slower (not shown). More discussion of the impact of the nighttime boundary-layer structure and its depth on the morning transition is given in Beare (2008).

\subsection{Vertical Structure}

Figures 10, 11 and 12 show vertical profiles at 1400 LT 23 October. Figure 10 shows the potential temperature structure from the SCM, LES, sounding and central tower. Most models show temperature profiles with a similar shape to those observed; a strongly decreasing temperature in the lowest $50-100 \mathrm{~m}$ and a near-adiabatic profile above and until the inversion region is reached at about $800 \mathrm{~m}$. The capping inversion strengths are similar to those observed in most of the TKE models (panel $\mathrm{c}$ and d). The first-order models with the first grid point close to the surface all have a very similar profile shape to the observations and the LES in the upper part of the mixed layer, between 600 and $850 \mathrm{~m}$, with a slightly positive potential temperature gradient, consistent with non-local mixing by dry convection (e.g. Holtslag and Boville 1993). The TKE models are not able to reproduce this feature due to their local nature and produce a neutral or unstable profile throughout the PBL.

A few of the models, mostly those with coarser resolution within the PBL, are still in the transition phase and do not generate a deep mixed layer until a later stage (see also Fig. 10). These models are found in both types of closures (panel $\mathrm{b}$ and $\mathrm{d}$ ). The spread in temperature at mid-height in the mixed layer is up to $5^{\circ} \mathrm{C}$, which is more than that found in the near-surface temperature (Fig. 3). The LES results show colder air than the observations, especially in 


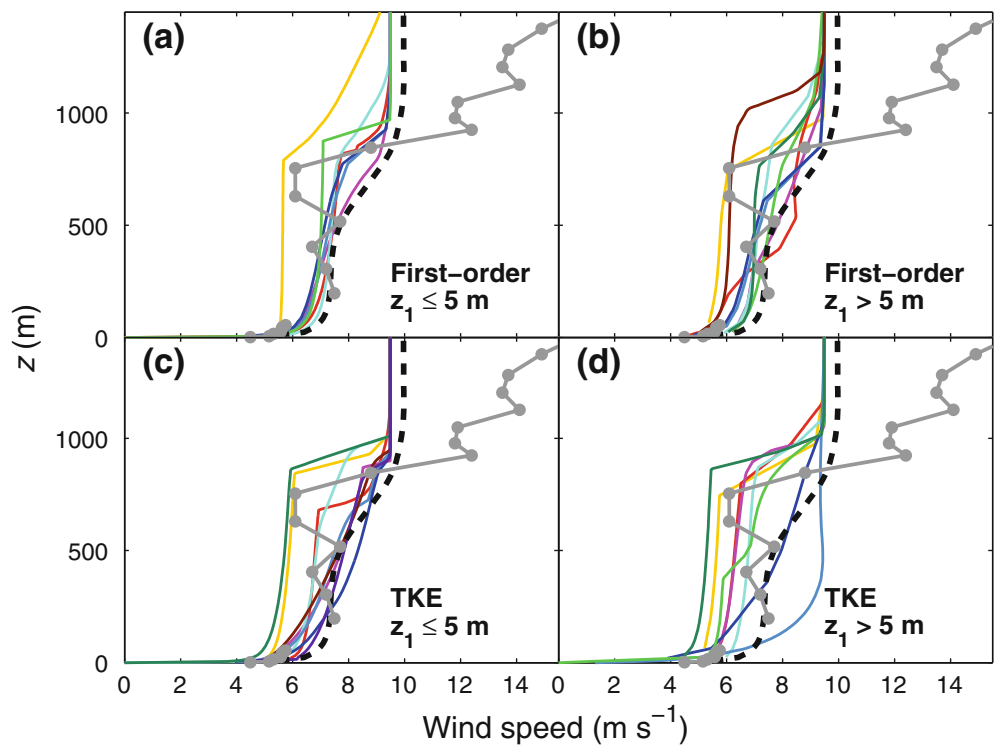

Fig. 11 Observed (grey, combined from tower and sounding) and modelled vertical profiles of wind speed $\left(\mathrm{m} \mathrm{s}^{-1}\right)$ at 1400 LT 23 October. Otherwise as in Fig. 3

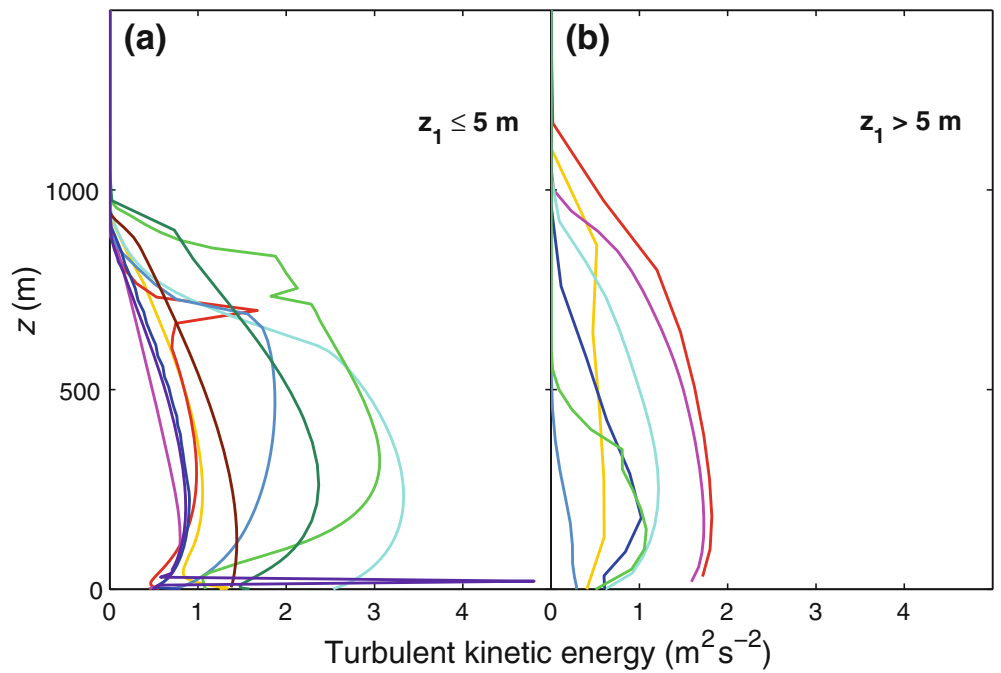

Fig. 12 Modelled vertical profiles of turbulent kinetic energy $\left(\mathrm{m}^{2} \mathrm{~s}^{-2}\right)$ at 1400 LT 23 October. Otherwise as in Fig. 8

the lower $500 \mathrm{~m}$. Some of the first-order SCMs with coarser vertical resolution (Fig. 10b), produce no well-defined capping inversion; they show only gradually increasing stable stratification with height. Hence, the influence of entrainment and/or the turbulent length scale in the stably stratified inversion region is expected to have had an impact. Depending on the model formulation, this may influence entrainment and turbulence in the stably stratified inversion region. 
The inter-model spread for the wind speed is even more pronounced than for the temperature (Fig. 11). Again, models with first-order closures and with finer vertical resolution give the most coherent picture. In this category, there is a clear outlier (ACM2) with a lower wind speed all through the mixed layer. It is also interesting to note how the slightly stably stratified upper part of the PBL in the LES appears to affect the wind profile, which is approximately constant up to about $500 \mathrm{~m}$, while the PBL depth is about $800 \mathrm{~m}$. The observations here show a rather variable profile possibly indicating a convective and horizontally inhomogeneous instantaneous picture. Other observations (from sodar and wind profilers, not shown) give a near-constant wind speed of about $5.5-6.5 \mathrm{~m} \mathrm{~s}^{-1}$ in the well-mixed PBL, with slightly lower values in the upper part, and a strong increase in the inversion region as also shown in the sounding (Fig. 11). The increase is not seen in the SCM or LES because of the constant geostrophic wind that was imposed (see Appendix and Fig. 1). The TKE models show the largest variability at about $500 \mathrm{~m}$. The observations show a wind speed of about $7 \mathrm{~m} \mathrm{~s}^{-1}$ while the SCM results show values between 5 and $9.5 \mathrm{~m} \mathrm{~s}^{-1}$.

Profiles of TKE are presented in Fig. 12. Again, there is large diversity in the modelled values as was also apparent in Fig. 8. These daytime dry convective PBLs have very different energy levels as well as different shapes. The height of the maximum TKE for each SCM occurs as low as $100 \mathrm{~m}$ and as high as $850 \mathrm{~m}$ while most have the maximum in the lower half of the PBL. Unfortunately, there are no observations throughout the PBL to compare with.

\subsection{Conservation of Heat}

The growth of the PBL during the morning hours after the onset of convection is driven by the upward surface heat fluxes. The heat that is received by the PBL is used to form a well-mixed boundary layer that entrains potentially warm air from above the capping inversion. From Fig. 4, one can infer that the integrated heat input from the surface is very different in the various SCMs. Starting from the equation for conservation of heat (Stull 1988), acknowledging that we are studying a horizontally homogeneous PBL with no interaction with radiation, we arrive at the following equation:

$$
\frac{\partial \bar{\theta}}{\partial t}=-\frac{\partial \overline{w^{\prime} \theta^{\prime}}}{\partial z}=-\frac{1}{\rho C_{\mathrm{p}}} \frac{\partial H}{\partial z^{\prime}},
$$

where $\theta$ is the potential temperature, and the right-hand side expression is for the effect of the turbulent transport of heat (molecular diffusion is neglected). Integration of (3) from the surface to a height well above the PBL top $\left(z_{\mathrm{h}}\right)$ yields

$$
\int_{z=0}^{z=z_{\mathrm{h}}} \rho \frac{\partial \bar{\theta}}{\partial t} \mathrm{~d} z=-\frac{1}{C_{\mathrm{p}}} \int_{H(z=0)=H_{0}}^{H\left(z_{\mathrm{h}}\right)=0} \mathrm{~d} H=\frac{H_{0}}{C_{\mathrm{p}}} .
$$

Integrating (4) from the time when the surface heat flux turns positive ( $\left.t_{0}\right)$ to time $t$ gives

$$
\int_{t_{0}}^{t} \int_{z=0}^{z=z \mathrm{~h}} \rho \partial \bar{\theta} \mathrm{d} z=\frac{1}{C_{\mathrm{p}}} \int_{t_{0}}^{t} H_{0} \mathrm{~d} t .
$$

Figure 13 plots the integrated surface heat flux against the change in heat content of the PBL derived from the hourly profiles of temperature following (5). If energy is conserved, then these two quantities should be equal at all times (every hour in this case). In the calculations, the entrainment flux is not a net source of energy since we are considering the whole column. 


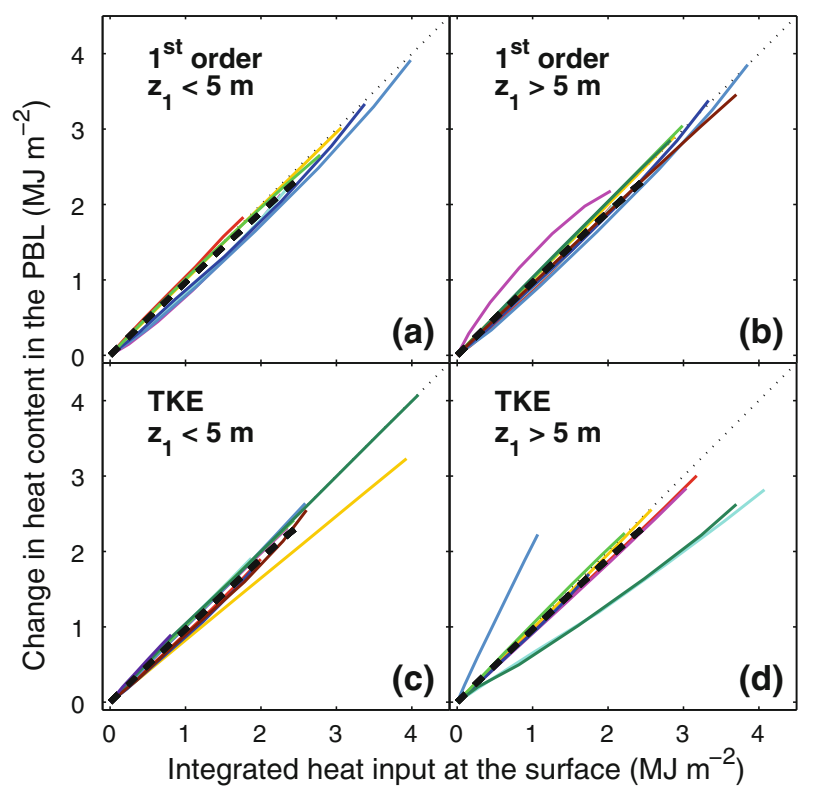

Fig. 13 Integrated heat input at the surface to the PBL $\left(\mathrm{MJ} \mathrm{m}^{-2}\right)$ plotted versus the change in heat content of the PBL $\left(\mathrm{MJ} \mathrm{m}^{-2}\right)$ for each hour after the PBL turned convective. Otherwise as in Fig. 3

As seen in Fig. 13, most models conserve heat. Small deviations from the line can be due to the time and space resolution of the model output and/or assumptions in density calculations. However, a few models seem to have an implementation problem since they deviate strongly from the one-to-one line, including the WRF-MYJ where possibly the effect of the limited friction velocity plays a role. Most models that deviate strongly from the line are found in the coarse-resolution category (panel d). The cumulative heat input used to grow the PBL in the SCM differs by more than a factor of four between the models (only including the models that are approximately on the one-to-one line). The lowest value is less than $800 \mathrm{~kJ} \mathrm{~m}^{-2}$, and the highest received more than $3500 \mathrm{~kJ} \mathrm{~m}^{-2}$ while the LES gives about $2000 \mathrm{~kJ} \mathrm{~m}^{-2}$. Based on this analysis, it is quite clear that the experimental design employed resulted in a variety of PBL evolutions.

\section{General Characteristics of the Diurnal Cycle}

As is clear from Figs. 3 and 5, the response of the individual models to the prescribed diurnal temperature forcing (with amplitude of $19^{\circ} \mathrm{C}$ ) is very different. At the onset of convection, the observations on 23 October show an increase over $1 \mathrm{~h}$ in the wind speed of about $3 \mathrm{~m} \mathrm{~s}^{-1}$. The question may arise whether we have selected an atypical day for our study. To place these findings into perspective, we have analyzed the diurnal cycle for the entire month of data from CASES-99, both for the near-surface temperature as well as for wind speeds at two heights. From each diurnal cycle, we have removed the mean value. This allows us to look at the daily amplitude in isolation from the magnitude of the background wind, with the assumption that the diurnal signal is strong in all the cases. For this calculation, all seven stations within the outer larger area are included in the near-surface calculations. 


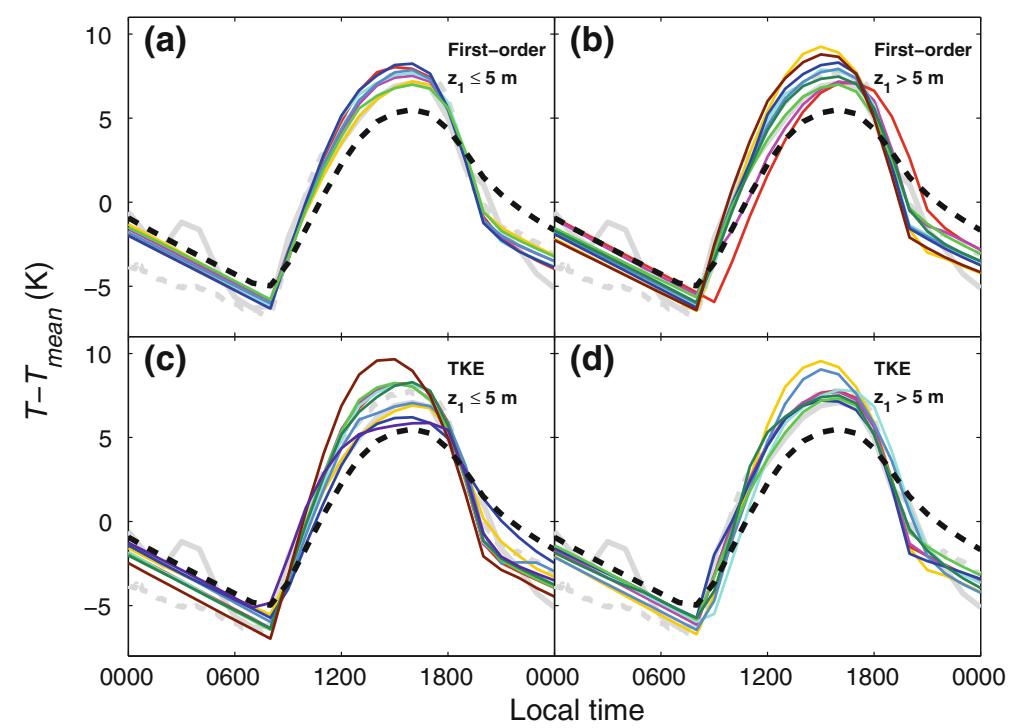

Fig. 14 Time series of observed and modelled temperature deviation $\left({ }^{\circ} \mathrm{C}\right)$ at $2 \mathrm{~m}$ a.g.1. Light grey solid line is the selected experiment period, the light grey dashed line shows the average over the entire CASES-99 campaign. Otherwise as in Fig. 3

As is seen in Fig. 14, the diurnal variation for the studied period is very similar to the average over the month. The difference in amplitudes is less than $1{ }^{\circ} \mathrm{C}$, and the two curves follow each other very well during the daytime. The amplitudes of the SCMs and LES are more variable, with the LES having the smallest diurnal amplitude. It is also noted that the minimum and maximum average temperatures (subtracted in Fig. 14) of first-order models with the lowest grid point below $5 \mathrm{~m}$ (panel a) are 6.2 and $6.9^{\circ} \mathrm{C}$, respectively. The corresponding numbers for the remaining categories are: 6.2 and $8.6^{\circ} \mathrm{C}$ for panel b; 5.7 and $7.2^{\circ} \mathrm{C}$ for panel c; and 6.3 and $7.2^{\circ} \mathrm{C}$ for panel $\mathrm{d}$. The averaged temperature for the diurnal cycle for the LES is $6.0^{\circ} \mathrm{C}$, and the observations of the day $6.6^{\circ} \mathrm{C}$. In particular, the afternoon cooling is much slower in the LES than in both the SCMs and observations.

The monthly averaged increase in wind speed for the night-to-day transition is $2.5 \mathrm{~m} \mathrm{~s}^{-1}$ with the actual case giving a slightly larger increase of about $3 \mathrm{~m} \mathrm{~s}^{-1}$; almost none of the models capture this sharp increase (Fig. 15). The exception is the CAM-UW that has a strong increase at the right time. However, the greater wind speed is only present for an hour while, in the observations, the wind speed at $10-\mathrm{m}$ height is almost constant during the convective part of the day. The wind speed increases slightly in the monthly mean data while decreasing on this particular day, possibly due to the decline in the large-scale forcing (Fig. 1). At the morning transition, some models have a temporary fall in wind speed as is also seen in the observations (Fig. 15). Other models have a sudden small increase in wind speed at the time of the transition followed by a decrease. The lower wind speeds are then maintained until the PBL has grown to encompass the entire residual layer with the possibility to transport momentum from the stronger winds aloft. The impact of the boundary layer growing into the residual layer increases the near-surface winds that in turn influence the surface driven turbulence and the further growth of the PBL. Some models, however, do not show any increase at the morning transition but later when the PBL has encompassed the residual layer (e.g. WRF-MYJ). 


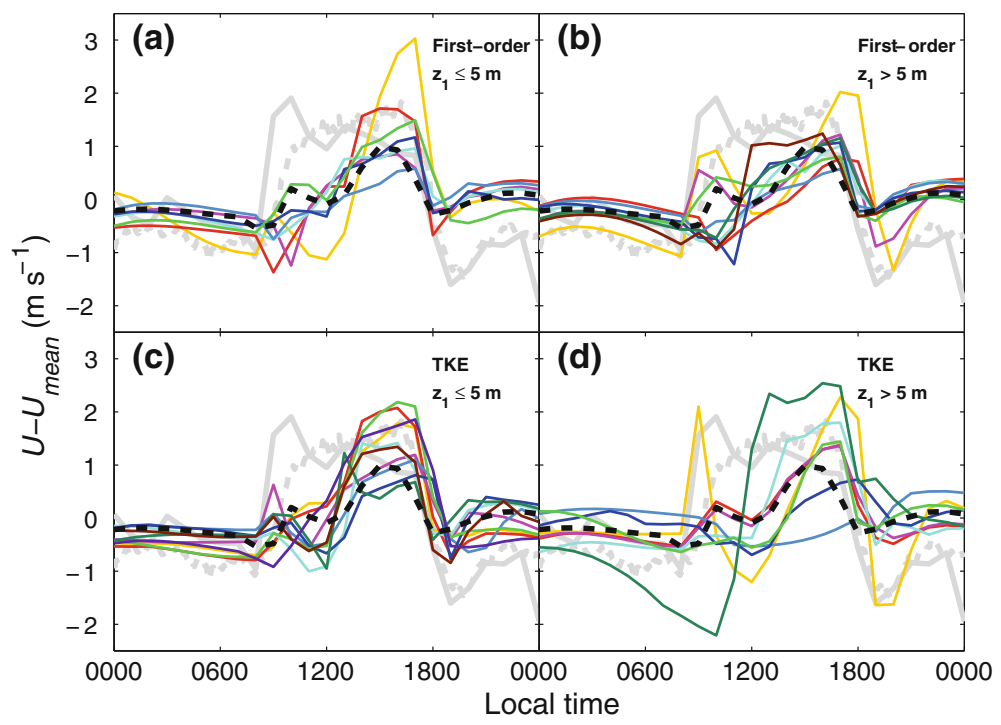

Fig. 15 Time series of observed and modelled wind speed deviation $\left(\mathrm{ms}^{-1}\right)$ at $10 \mathrm{~m}$ a.g.1. Light grey solid line is the selected experiment period, the light grey dashed line shows the average over the entire CASES-99 campaign. Otherwise as in Fig. 3

At the evening transition, i.e. when going from a well-mixed PBL to a stably stratified layer, most models show a sudden decrease in the wind speed-however not as large as the observed decrease (Fig. 15). The exception here seems to be the TKE-based models with coarser vertical resolution where we find both models with a similar strong decrease to that observed (CAM-UW) and models with the opposite diurnal cycle (LaRC). Remember that for all model results, the averaged wind for the diurnal cycle is removed in Fig. 15. The minimum and maximum diurnal averages in the wind speed for first-order models with lowest grid point below $5 \mathrm{~m}$ (panel a) is 3.8 and $4.9 \mathrm{~m} \mathrm{~s}^{-1}$, respectively. The corresponding values for the remaining categories are: 3.4 and $6.2 \mathrm{~m} \mathrm{~s}^{-1}$ for panel $\mathrm{b} ; 3.6$ and $4.9 \mathrm{~m} \mathrm{~s}^{-1}$ for panel $\mathrm{c}$; and 2.4 and $6.0 \mathrm{~m} \mathrm{~s}^{-1}$ for panel $\mathrm{d}$. The averaged wind speed for the diurnal cycle for the LES is $5.0 \mathrm{~m} \mathrm{~s}^{-1}$ and the observations of the day $4.0 \mathrm{~m} \mathrm{~s}^{-1}$.

Figure 16 shows the deviation from the mean wind speeds at the highest observation point on the central tower $(55 \mathrm{~m}$ a.g.l). Here, we clearly see that the observations at this height show much less of a diurnal cycle, with slightly higher winds during the night than during day, indicating that this height is in the upper part of, or above, the nighttime PBL. All SCMs show a higher nighttime wind speed than during the day, with, in most cases, a strong minimum beginning at the morning transition and lasting until noon. The LES, however, does not generally show a stronger wind at night and only a small diurnal cycle-much more like the observations. The first-order models with coarser vertical resolution give results most comparable to the observations (panel b), while all the TKE models with finer resolution show far too much variability and too strong an amplitude at this height. The observations for this day and the LES both show a mean wind speed of $6.9 \mathrm{~m} \mathrm{~s}^{-1}$ while the different SCMs give the following ranges $2.5-8.0 \mathrm{~m} \mathrm{~s}^{-1}$ (panel a); $3.9-7.5 \mathrm{~m} \mathrm{~s}^{-1}$ panel (b); $6.3-8.3 \mathrm{~m} \mathrm{~s}^{-1}$ panel (c); and 4.7-8.3 $\mathrm{m} \mathrm{s}^{-1}$ panel (d). Thus, the TKE models with finer vertical resolution are in the category that is the closest to the observed mean wind speed. 


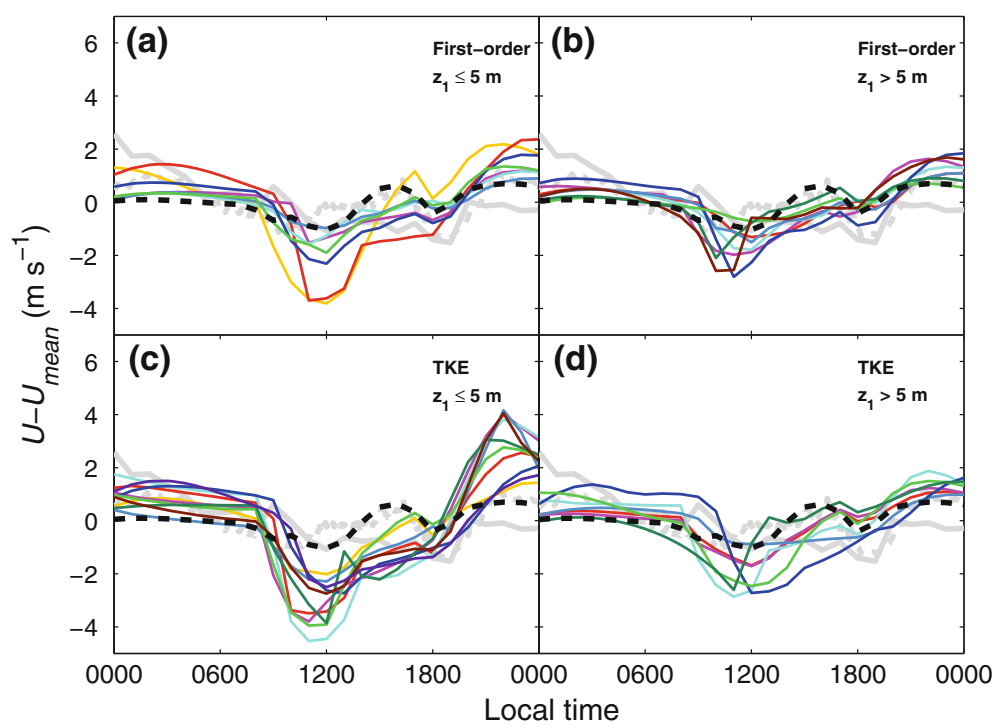

Fig. 16 Time series of observed and modelled wind speed deviation $\left(\mathrm{m} \mathrm{s}^{-1}\right)$ at $55 \mathrm{~m}$ a.g.1. Light grey solid line is the selected experiment period, the light grey dashed line shows the average over the entire CASES-99 campaign. Otherwise as in Fig. 3

\section{Discussion and Conclusions}

The experimental design taken for the second GABLS experiment appears to present a tough test for the models. This is partly due to the chosen forcing with prescribed surface temperature. It is clear from the present analysis that the prescribed surface temperature is not seen in the same way by the various models, and discrepancies are introduced by this method. If, on the other hand, the surface heat flux had been selected as the boundary condition, then this would have created variable surface temperatures among the models. Basu et al. (2008), among others, have shown that using the heat flux as a lower boundary condition is not a proper method to force a stably stratified boundary layer. A land-surface model could have been used for the lower boundary condition but that would have resulted in differences in the model results for both the surface temperature and heat fluxes. In this case, the intercomparison would not have been only for the PBL schemes, as we aimed for, but would also include the land-surface schemes (as in GABLS3, Bosveld et al. 2008). Further discussions on the issue of the sensitivity to the boundary condition for the GABLS2 set-up can be found in Holtslag et al. (2007) and Kumar et al. (2010). Ultimately, the selected method of using prescribed surface temperature turned out to be a far more difficult test of the PBL closures than anticipated. This is clear even early on in the simulated 2-m temperature.

The decision to apply constant geostrophic forcing, and omit large-scale advection, limits the comparability with the observations. Thus, the analysis is extended to encompass the entire month of the CASES-99 observations to examine the representativeness of the selected diurnal cycle. Furthermore, results from an LES, forced identically as the SCM (Kumar et al. 2010), are included. The analysis leads to the following conclusions:

- The selected experiment period displays a typical diurnal cycle for the month of October in Kansas, USA, according to the CASES-99 observations. 
- The diurnal amplitude in the 2-m temperature modelled by the SCMs is as large, or larger than the observed one. The LES is warmer than most SCMs during night and cooler during day, resulting in a significant underprediction of the diurnal amplitude.

- The differences in low-level temperature manifest themselves through differences in the low-level stability in turn affecting the turbulence and thus the turbulent heat fluxes. The general findings for all model closures and the LES are that the magnitude of the sensible heat flux is overestimated during night and underestimated during day. In particular, the increase during the hours after the morning transition is too weak and the growth of the convective PBL before noon is far too slow.

- The weak turbulence during the morning hours is apparent in the modelled and simulated low-level wind speed. This could be due to insufficient entrainment of momentum (Angevine et al. 2001; Angevine 2008). The observed sudden increase of about $3 \mathrm{~m} \mathrm{~s}^{-1}$ at the morning transition is neither captured by the majority of the models nor the LES; if captured, it is not maintained at the higher level shown in observations during the hours until noon. The mean diurnal wind speed is also very different in the models, ranging from 2.4 to $6.2 \mathrm{~m} \mathrm{~s}^{-1}$ and 2.5 to $8 \mathrm{~m} \mathrm{~s}^{-1}$ at 10 and $55 \mathrm{~m}$ a.g.l., respectively.

- The agreement between the SCMs, the LES and observations is best during the late afternoon when the near-surface levels of turbulence in the models are stronger. However, when examining the vertical profiles at 1400 LT there are considerable differences in the shape and magnitude of the modelled and simulated temperatures and winds. The strengths of the capping inversion and entrainment zone are generally better modelled with the TKE schemes while the slightly stably stratified upper part of the mixed layer is better reproduced by some first-order schemes due to their non-local formulations.

From this intercomparison study, we find that modelling the diurnal cycle presents a big challenge. Overall, some of the first-order schemes perform somewhat better in the convective part of the diurnal cycle, while the TKE schemes tend to be slightly better during nighttime conditions. The latter is probably related to the more realistic short-tail type mixing in these models (see also Cuxart et al. 2006). The models with their first model level closer to the surface tend to produce somewhat better near-surface results in agreement with the analysis of GABLS1 (Svensson and Holtslag 2009). However, during the morning transition and the following hours, the LES and all SCMs do not perform satisfactorily regardless of vertical resolution.

Confronting boundary-layer models with observations remains a difficult task. Nevertheless, the experience gained with this study has inspired and guided the GABLS community to set-up a new intercomparison case for SCM and LES using Cabauw observations (Bosveld et al. 2008).

Acknowledgments The authors thank the CASES-99 community and colleagues at Wageningen University for arranging the observations. The authors also acknowledge the involvement and many constructive remarks by Michael Tjernström, Bas van de Wiel and many others in the GABLS community and the participating modelling groups. We are grateful to CIRES and NCAR for their support, and for hosting the first author while working on this article. A.A.M. Holtslag and G.J. Steeneveld acknowledge the support provided by the Dutch BSIK-ME2 research program.

\section{Appendix}

The following list of instructions concerning model set-up and forcings was distributed to the participating modelling groups along with instructions on how to submit the data. The study 
period begins at 1600 LT 22 October and continues for $59 \mathrm{~h}$. The location of the experiment is $37.6^{\circ} \mathrm{N}, 96.7^{\circ} \mathrm{E}$.

- The set-up requires a minimum vertical domain of $4000 \mathrm{~m}$ with preferably log-linearly distributed gridpoints with the first point close to the ground $O(1 \mathrm{~m})$ and at least $100-\mathrm{m}$ resolution close to the model top. If a model has a specific operational grid, then this may also be used.

- A timestep appropriate for the vertical resolution should be used.

- Radiation scheme should be turned off.

- Surface pressure at initial time is $972 \mathrm{hPa}$ (The location is at $436 \mathrm{~m}$ a.s.1.).

- Aerodynamic roughness length is set to $z_{0}=0.03 \mathrm{~m}$, and the thermal roughness length is set as $z_{\mathrm{T}}=z_{0} / 10$.

- The latent heat flux at the surface is set to $2.5 \%$ of its potential value, i.e. the value given by a land surface saturated with water at the prescribed temperature.

- Values of constants to be used: gravitational acceleration $g=9.81 \mathrm{~m} \mathrm{~s}^{-2}$; reference temperature $\theta_{0}=283.15 \mathrm{~K}$ and reference pressure $p_{0}=1000 \mathrm{hPa}$.

- Geostrophic wind is constant with height and time with $u_{\mathrm{g}}=3 \mathrm{~m} \mathrm{~s}^{-2}$ and $u_{\mathrm{g}}=-9 \mathrm{~m} \mathrm{~s}^{-2}$

- Large-scale synoptic divergence is introduced at 1600 LT 23 October and is kept constant for the remainder of the integration, resulting in a vertical wind given by $w=-0.005 \frac{z}{1000} \mathrm{~ms}^{-1}$ below the height $z=1000 \mathrm{~m}$ and a constant value of $w=$ $-0.005 \mathrm{~m} \mathrm{~s}^{-1}$ above.

- Initial vertical profiles of potential temperature $(\theta)$ and specific humidity $(q)$ valid at 1600 LT:

\begin{tabular}{llr}
\hline$\Theta(\mathrm{K})$ & $q\left(\mathrm{~kg} \mathrm{~kg}^{-1}\right)$ & $z(\mathrm{~m})$ \\
\hline 288 & 0.0025 & 0 \\
286 & 0.0025 & 200 \\
286 & 0.0025 & 850 \\
288 & 0.0025 & 900 \\
292 & 0.0005 & 1000 \\
300 & 0.0030 & 2000 \\
310 & 0.0020 & 3500 \\
312 & 0.0015 & 4000 \\
\hline
\end{tabular}

- The skin temperature in ${ }^{\circ} \mathrm{C}$ is given as a function of local time $t$ in hours (+24 or 48 for 23 and 24 October, respectively):

\begin{tabular}{ll}
\hline$T=-10-25 \cos (0.22 t+0.2)$ & $t \leq 17.4$ \\
$T=-0.54 t+15.2$ & $17.4>t \leq 30$ \\
$T=-7-25 \cos (0.21 t+1.8)$ & $30<t \leq 41.9$ \\
$T=-0.37 t+18.0$ & $41.9>t \leq 53.3$ \\
$T=-4-25 \cos (0.22 t+2.5)$ & $53.3<t \leq 65.6$ \\
$T=4.4$ & $t>65.6$ \\
\hline
\end{tabular}

\section{References}

Andrén A (1990) Evolution of a turbulence closure scheme suitable for air-pollution applications. J Appl Meteorol 29:224-239. doi:10.1175/1520-0450(1990)029<0224:EOATCS>2.0.CO;2

Angevine WM (2008) Transitional, entraining, cloudy, and coastal boundary layers. Acta Geophys 56:2-20

Angevine WM, Baltink HK, Bosveld FC (2001) Observations of the morning transition of the convective boundary layer. Boundary-Layer Meteorol 101:209-227 
Basu S, Holtslag AAM, van de Wiel BJH, Moene AF, Steeneveld GJ (2008) An inconvenient "truth" about using sensible heat flux as a surface boundary condition in models under stably stratified regimes. Acta Geophys 56:88-99

Bazile E, Beffrey G, Joly M, Marzouki M (2005) Interactive mixing length and modifications of the exchange coefficient for the stable case. ALADIN News1 27:152-156

Beare RJ (2008) The role of shear in the morning transition boundary layer. Boundary-Layer Meteorol 129:395-410. doi:10.1007/s10546-008-9324-8

Beare RJ, MacVean MK, Holtslag AAM, Cuxart J, Esau I, Golaz J-C, Jimenez MA, Khairoutdinov M, Kosovic B, Lewellen D, Lund TS, Lundquist JK, McCabe A, Moene AF, Noh Y, Raasch S, Sullivan PP (2006) An intercomparison of large-eddy simulations of the stable boundary layer. Boundary-Layer Meteorol 118:247-272. doi:10.1007/s10546-004-2820-6

Bélair S, Mailhot J, Strapp JW, MacPherson JI (1999) An examination of local versus nonlocal aspects of a TKE-based boundary-layer scheme in clear convective conditions. J Appl Meteorol 38:1499-1518

Beljaars ACM, Holtslag AAM (1991) Flux parameterization over land surfaces for atmospheric models. J Appl Meteorol 30:327-341

Bosveld FC, de Bruijn C, Holtslag AAM (2008) Intercomparison of single-column models for GABLS3 preliminary results. In: The symposium on boundary layers and turbulence, Stockholm, Sweden, American Meteorological Society, 8A.5, preprint

Bougeault P, Lacarrère P (1989) Parameterization of orography-induced turbulence in a meso-beta-scale model. Mon Weather Rev 117:1872-1890

Bouteloup Y, Bazile E, Bouyssel F, Marquet P (2009) Evolution of the physical parametrizations of ARPEGE and ALADIN-MF. ALADIN News1 35:48-58

Bou-Zeid E, Meneveau C, Parlange MB (2005) A scale-dependent Lagrangian dynamic model for large eddy simulation of complex turbulent flows. Phys Fluids 17:025105

Bretherton C, Park S (2009) Moist turbulence parameterization in the community atmosphere model. J Clim $12: 3422-3448$

Brutsaert WH (1982) Evaporation into the atmosphere. Reidel, Dordrecht

Cuxart J, Bougeault P, Redelsperger J-L (2000) A turbulence scheme allowing for mesoscale and large-eddy simulations. Q J R Meteorol Soc 126:1-30

Cuxart J, Holtslag AAM, Beare RJ, Bazile E, Beljaars A, Cheng A, Conangla L, Ek M, Freedman F, Hamdi R, Kerstein A, KitagawaH , Lenderink G, Lewellen D, Mailhot J, Mauritsen T, Perov V, Schayes G, Steeneveld G-J, Svensson G, Taylor P, Weng W, Wunsch S, Xu K-M (2006) Single-column model intercomparison for a stably stratified atmospheric boundary layer. Boundary-Layer Meteorol 118:273-303. doi:10.1007/s10546-005-3780-1

Dai A, Trenberth KE (2004) The diurnal cycle and its depiction in the community climate system model. J Clim 5:930-951

Deardorff JW (1980) Stratocumulus-capped mixed layers derived from a three dimensional model. Boundary-Layer Meteorol 7:199-226

Dudhia J (2005) The weather research and forecast model version 2: update. WRF/MM5 users' workshop, June 2005

Duynkerke PG (1991) Radiation fog: a comparison of model simulation with detailed observations. Mon Weather Rev 119:324-341

Freedman FR, Jacobson MZ (2002) Transport-dissipation analytical solutions to the E-epsilon turbulence model and their role in predictions of the neutral ABL. Boundary-Layer Meteorol 102:117-138

Freedman FR, Jacobson MZ (2003) Modification of the standard epsilon-equation for the stable ABL through enforced consistency with Monin-Obukhov similarity theory. Boundary-Layer Meteorol 106:383-410

Golaz J-C, Larson VE, Cotton WR (2002) A PDF-based model for boundary layer clouds, part I: method and model description. J Atmos Sci 59:3540-3551

Hartogensis OK, de Bruin HAR (2005) Monin-Obukhov similarity functions of the structure parameter of temperature and turbulent kinetic energy dissipation rate in the stable boundary layer. Boundary-Layer Meteorol 116:253-276

Hodur RM (1997) The Naval Research Laboratory's Coupled Ocean/Atmosphere Mesoscale Prediction System (COAMPS). Mon Weather Rev 125:1414-1430

Holtslag AAM (2003) GABLS initiates intercomparison for stable boundary layers. GEWEX News 13:7-8

Holtslag AAM (2006) GEWEX Atmospheric Boundary-Layer Study (GABLS) on stable boundary layers. Boundary-Layer Meteorol 118:243-246

Holtslag AAM, Boville B (1993) Local versus nonlocal boundary-layer diffusion in a global climate model. J Clim 6:1825-1842

Holtslag AAM, Steeneveld GJ, van de Wiel BJH (2007) Role of land-surface temperature feedback on model performance for the stable boundary layer. Boundary-Layer Meteorol 118:273-303 
Hong SY, Pan HL (1996) Non-local boundary layer diffusion in a medium-range forecast model. Mon Weather Rev 124:2322-2339

Kumar V, Kleissl J, Meneveau C, Parlange MB (2006) Large-eddy simulation of a diurnal cycle in the turbulent atmospheric boundary layer: atmospheric stability and scaling issues. Water Resour Res 42:W06D09

Kumar V, Svensson G, Holtslag AAM, Parlange MB, Meneveau C (2010) Impact of surface flux formulations and geostrophic forcing on large-eddy simulations of the diurnal atmospheric boundary layer flow. J Meteorol Climatol 49:1496-1516. doi:10.1175/2010JAMC2145.1

Lafore JP, Stein J, Asencio N, Bougeault P, Ducrocq V, Duron J, Fischer C, Héreil P, Mascart P, Masson V, Pinty JP, Redelsperger JL, Richard E, de Arellano JV-G (1998) The Méso-NH atmospheric simulation system, part I: adiabatic formulation and control simulation. Ann Geophys 16:90-109

Larson VE, Golaz J-C (2005) Using probability density functions to derive consistent closure relationships among higher-order moments. Mon Weather Rev 133:1023-1042

LeMone MA, Grossman RL, Coulter RL, Wesley ML, Klazura GE, Poulos GS, Blumen W, Lundquist JK, Cuenca RH, Kelly SF, Brandes EA, Oncley SP, McMillen RT, Hicks BB (2000) Land-atmosphere interaction research, early results, and opportunities in the Walnut River Watershed in southeast Kansas: CASES and ABLE. Bull Am Meteorol Soc 13:757-779

Lenderink G, Holtslag AAM (2004) An updated length scale formulation for turbulent mixing in clear and cloudy boundary layers. Q J Roy Meteorol Soc 130:3405-3428

Lock AP, Brown AR, Bush MR, Martin GM, Smith RNB (2000) A new boundary layer mixing scheme, part I: scheme description and single-column model tests. Mon Weather Rev 128:3187-3199

Louis JF (1979) A parametric model of the vertical eddy fluxes in the atmosphere. Boundary-Layer Meteorol 17:187-202

Mauritsen T, Svensson G, Zilitinkevich S, Esau I, Enger L, Grisogono B (2007) A total turbulent energy closure model for neutral and stably stratified atmospheric boundary layers. J Atmos Sci 64:4113-4126

Mellor GL, Yamada T (1974) A hierarchy of turbulence closure models for planetary boundary layers. J Atmos Sci 31:1791-1806

Noh Y, Cheon WG, Hong SY, Raasch S (2003) Improvement of the K-profile model for the planetary boundary layer based on large-eddy simulation data. Boundary-Layer Meteorol 107:401-427

Pleim JE (2007a) A combined local and non-local closure model for the atmospheric boundary layer, part 1: model description and testing. J Appl Meteorol Climatol 46:1383-1395

Pleim JE (2007b) A combined local and non-local closure model for the atmospheric boundary layer, part 2: application and evaluation in a mesoscale meteorology model. J Appl Meteorol Climatol 46:1396-1409

Poulos GS et al (2002) CASES-99: a comprehensive investigation of the stable nocturnal boundary layer. Bull Am Meteorol Soc 83:555-581

Redelsperger J-L, Mahé F, Carlotti P (2001) A simple and general subgrid model suitable both for surface layer and free-stream turbulence. Boundary-Layer Meteorol 101:375-408

Skamarock WC, Klemp JB, Dudhia J, Gill DO, Barker DM, Duda M, Huang X-Y, Wang W, Powers JG (2008) A description of the advanced research WRF version 3. NCAR Technical Note TN-475

Steeneveld GJ, van de Wiel BJH, Holtslag AAM (2006) Modeling the evolution of the atmospheric boundary layer coupled to the land surface for three contrasting nights in CASES-99. J Atmos Sci 63:920-935

Steeneveld GJ, Mauritsen T, de Bruijn EIF, de Arellano JV-G, Svensson G, Holtslag AAM (2008) Evaluation of limited area models for the representation of the diurnal cycle and contrasting nights in CASES99. J Appl Meteorol Climatol 47:869-887

Stull R (1988) An introduction to boundary layer meteorology. Kluwer Academic Publishers, Dordrecht

Svensson G, Holtslag AAM (2009) Modelling the turning of wind with height in the stable boundary layer. Boundary-Layer Meteorol 132:261-277

Teixeira J, Stevens B, Bretherton CS, Cederwall R, Doyle JD, Golaz JC, Holtslag AAM, Klein SA, Lundquist JK, Randall DA, Siebesma AP, Soares PMM (2008) Parameterization of the atmospheric boundary layer: a view from just above the inversion. Bull Am Meteorol Soc 89:453-458

Tjernström M, Žagar M, Svensson G, Cassano J, Pfeifer S, Rinke A, Wyser K, Dethloff K, Jones C, Semmler T (2005) Modeling the Arctic boundary layer: an evaluation of six ARCMIP regional-scale models with data from the SHEBA project. Boundary-Layer Meteorol 117:337-381

Tomas S, Masson V (2006) A parameterization of third order moments for the convective boundary layer. Boundary-Layer Meteorol 120:437-454

Tompkins AM, Bechtold P, Beljaars ACM, Benedetti A, Cheinet S, Janisková M, Köhler M, Lopez P, Morcrette J-J (2004) Moist physical processes in the IFS: progress and plans. ECMWF Technical Memorandum $\mathrm{Nr} 452$

Undén P, Rontu L, Järvinen H, Lynch P, Calvo J et al (2002) The HIRLAM-5 scientific documentation. http://hirlam.org 
Vickers D, Mahrt L (2003) The cospectral gap and turbulent flux calculations. J Atmos Ocean Technol 20: 660-672

Weng W, Taylor PA (2006) Modelling the 1D stable boundary layer with an E-1 turbulence closure scheme. Boundary-Layer Meteorol 118:305-323

Xue M, Drogemeier KK, Wong V (2000) The advanced regional prediction system (ARPS)—a multi-scale non-hydrostatic atmospheric simulation and prediction model, part I: model dynamics and verification. Meteorol Atmos Phys 75:161-193

Zampieri M, Malguzzi P, Buzzi A (2005) Sensitivity of quantitative precipitation forecasts to boundary layer parameterization: a flash flood case study in the Western Mediterranean. Nat Hazards Earth Syst Sci 5:603-612

Zhang D-L, Zheng W-Z (2004) Diurnal cycles of surface winds and temperatures as simulated by five boundary layer parameterizations. J Appl Meteorol 43:157-169 